\title{
Sequential generation of olfactory bulb glutamatergic neurons by Neurog2-expressing precursor cells
}

\author{
Eleanor Winpenny ${ }^{1}$, Mélanie Lebel-Potter ${ }^{2}$, Maria E Fernandez ${ }^{3}$, Monika S Brill ${ }^{4,5,6}$, Magdalena Götz ${ }^{4,5,6}$, \\ Francois Guillemot ${ }^{3}$ and Olivier Raineteau ${ }^{1,3^{*}}$
}

\begin{abstract}
Background: While the diversity and spatio-temporal origin of olfactory bulb (OB) GABAergic interneurons has been studied in detail, much less is known about the subtypes of glutamatergic OB interneurons.

Results: We studied the temporal generation and diversity of Neurog2-positive precursor progeny using an inducible genetic fate mapping approach. We show that all subtypes of glutamatergic neurons derive from Neurog2 positive progenitors during development of the OB. Projection neurons, that is, mitral and tufted cells, are produced at early embryonic stages, while a heterogeneous population of glutamatergic juxtaglomerular neurons are generated at later embryonic as well as at perinatal stages. While most juxtaglomerular neurons express the T-Box protein Tbr2, those generated later also express Tbr1. Based on morphological features, these juxtaglomerular cells can be identified as tufted interneurons and short axon cells, respectively. Finally, targeted electroporation experiments provide evidence that while the majority of $O B$ glutamatergic neurons are generated from intrabulbar progenitors, a small portion of them originate from extrabulbar regions at perinatal ages.

Conclusions: We provide the first comprehensive analysis of the temporal and spatial generation of $O B$ glutamatergic neurons and identify distinct populations of juxtaglomerular interneurons that differ in their antigenic properties and time of origin.
\end{abstract}

\section{Background}

The development of the olfactory bulb $(\mathrm{OB})$ is traditionally believed to occur in two phases. The initial stages of $O B$ development show many similarities to the development of the neocortex. The first cells to be born are the glutamatergic projection neurons, the mitral and tufted cells of the $\mathrm{OB}$, beginning at embryonic day (E) $11[1,2]$. The mitral cells are produced first, followed by the tufted cells in an inside-out sequence, with superficial tufted cells the last to be born. At this time, newborn $\mathrm{OB}$ neurons are born in the ventricular zone (VZ) of the $\mathrm{OB}$ region, from radial glia, as in other cortical regions. Newborn cells migrate radially to their final positions, where they differentiate.

As the production of excitatory projection neurons continues and begins to slow, a second developmental

\footnotetext{
* Correspondence: raineteau@hifo.uzh.ch

${ }^{1}$ Cambridge Centre for Brain Repair, Robinson Way, CB2 OPY Cambridge, UK
} Full list of author information is available at the end of the article phase starts with the arrival of GABAergic interneurons in the OB. Whilst some interneurons have an intrabulbar origin [3], most of them emanate first from the lateral ganglionic eminence [4], and then from the rostral migratory stream (RMS) [5] and subventricular zone (SVZ) [6]. The peak of interneuron production is at perinatal ages, and continues throughout adult life [7-9].

During development, neuronal specification relies on the differential expression of distinct transcription factors. The basic helix-loop-helix (bHLH) transcription factor Neurog2 has typically been associated with the development of glutamatergic neurons [10-14]. Neurog2 participates in a cascade of transcription factors comprising Pax6, Tbr2 and Tbr1, which together promote the generation of glutamatergic neurons in both the cortex and the hippocampus. In the developing cortex, Neurog2 has been proposed to be directly responsible for the activation of a cortical glutamatergic transcriptional pathway and the repression of GABAergic transcription factors such as

\section{() Biomed Central}


Dlx2 [14]. At later stages, Neurog2 is believed to act in sequence with Mash1 to regulate the transition of neuronal precursors from the VZ to the SVZ [15].

Various classes of glutamatergic $\mathrm{OB}$ neurons have been described: mitral and tufted cells, which project and transfer information to a number of extrabulbar areas in the brain [16]; and glutamatergic interneurons of the glomerular layer (GL), which are subdivided into external tufted cells [17] and short-axon cells [18]. These two subtypes of neurons show intrabulbar axonal projections and play important roles in the processing of olfactory information [17-20]. Here, we use an inducible genetic fate mapping of Neurog 2 precursors to study the temporal profile by which glutamatergic neuronal subtypes are generated. We provide a comprehensive analysis of the temporal generation of $\mathrm{OB}$ glutamatergic neurons and identify distinct populations of juxtaglomerular interneurons that differ in their antigenic properties and time of origin. Moreover, our results suggest that some glutamatergic juxtaglomerular neurons originate from extrabulbar regions at perinatal ages.

\section{Results}

\section{Expression pattern of Neurog2, Pax6 and Tbr1/2 during olfactory bulb development}

We first visualized the expression of Neurog2 at different time points by using heterozygous Neurog $2^{+/ G F P}$ mice, in which green fluorescent protein (GFP) is inserted into one copy of the Neurog2 gene (Figure 1A-C). Immunostaining for Neurog2 confirmed the restricted expression of GFP to Neurog2-positive (Neurog2(+)) progenitors, confirming previous results $[10,21]$ (Figure $1 \mathrm{~K}$ ). However, as the GFP degrades less rapidly than the Neurog2 protein, GFP revealed the immediate progeny of the Neurog2(+) cells. We investigated the pattern of Neurog $2^{+/ G F P}$ expression in the $\mathrm{OB}$ at three developmental stages: E13.5, that is, shortly after the formation of the OB has begun; E17.5; and postnatal day $(\mathrm{P}) 0[1]$. At all three time points there was high expression of Neurog $2^{+/ G F P}$ in distinct regions of the developing forebrain (Figure 1A-C). We observed that whereas the GFP cells at E13.5 appear to be born in the presumptive $\mathrm{OB}$, by E17 many cells are observed in the developing RMS. These cells express DCX (data not shown), suggesting that they migrate to the $\mathrm{OB}$ from more caudal ventricular regions.

In many regions of the brain, both during development and in the adult, specification of glutamatergic neurons has been associated with the sequential expression of transcription factors comprising Pax6, Neurog2, Tbr2 and Tbr1 [10,12]. All markers were expressed in the developing $\mathrm{OB}$ at E13.5, with partially overlapping patterns of expression. Comparison of the degree of overlap between these markers and Neurog2 (Figure 1D-F) or Neurog2 $2^{+/ G F P}$ (Figure $1 \mathrm{H}-\mathrm{J}$ ) revealed a similar sequential expression of these markers in the developing OB. We observed a radial pattern of expression of these transcription factors in the $\mathrm{OB}$ region, with the youngest cells found in the VZ expressing Pax6, followed by expression of Neurog2, Tbr2 and Tbr1 as the cells migrate outwards towards the OB periphery. While Neurog2 showed minimal co-localization with Tbr1, a larger number of Neurog $2^{+/ G F P}$ cells expressed this marker. Because of the longer half-life of GFP (see above), these results illustrate the expression of Tbr1 in the immediate progeny of Neurog2(+) progenitors. In contrast, both Neurog2(+) and Neurog2 $2^{+/ G F P}$ cells were negative for Dlx2, a homeodomain transcription factor expressed in GABAergic progenitors. Whilst both progenitor populations were present in the $\mathrm{OB}$ [3], they showed a clear spatial segregation, with Dlx2-progenitors showing a more caudal distribution than Neurog2(+) progenitors (Figure 1G).

\section{Fate mapping of Neurog2-expressing progenitors during olfactory bulb development}

In order to determine more precisely the contribution of Neurog2(+) progenitors to developmental OB neurogenesis, we next used mice expressing a tamoxifen-inducible Cre recombinase under the Neurog 2 promoter, that is, Neurog2iCreERT2 (see Materials and methods). In situ hybridization and immunodetection of Cre and Neurog2 revealed an overlapping pattern of the two markers (Additional file 1). These mice were crossed with RosaYFP or TaukiGFP reporter mice. The second of these reporter mice expresses a membrane bound form of GFP (see Materials and methods), allowing one to visualize the detailed morphology of the recombined cells [22]. Tamoxifen injections at E13.5, E17.5 and P0 induced a rapid recombination in a small number of Neurog2 expressing cells, observable as early as 24 hours post-injection (Additional file 2). At this short time point, immunodetection of Tbr2 and Dlx2 in the GFP(+) cells $(100 \%$ and $0 \%$ co-localization, respectively; 47 cells analyzed; Additional file 2) supports the restricted expression of the Cre recombinase, and the efficient labeling of the Neurog2 cell lineage.

We next investigated the fate of E13.5, E17.5 and P0 Neurog2(+) progenitors by quantifying $\operatorname{GFP}(+)$ cells in the OB layers at P21 (Figure 2). In all groups of mice, the vast majority of $\mathrm{GFP}(+)$ cells were observed in the mitral cell layer $(\mathrm{MCL})$, external plexiform layer (EPL) and GL, and only a very small number was observed in the granule cell layer. Animals injected at E13.5 had GFP cells with cell bodies in the MCL (42.3 $\pm 4.8 \%)$ and EPL $(40.6 \pm 3.3 \%)$. At this early embryonic time point, only a small population of $\mathrm{GFP}(+)$ cells was observed in the GL $(16.7 \pm 1.3 \%$; Figure $2 \mathrm{~A}, \mathrm{~B} ; 1,192 \mathrm{GFP}(+)$ cells analyzed in 3 animals). Measurement of the cell body diameter revealed a significant decrease from the MCL 


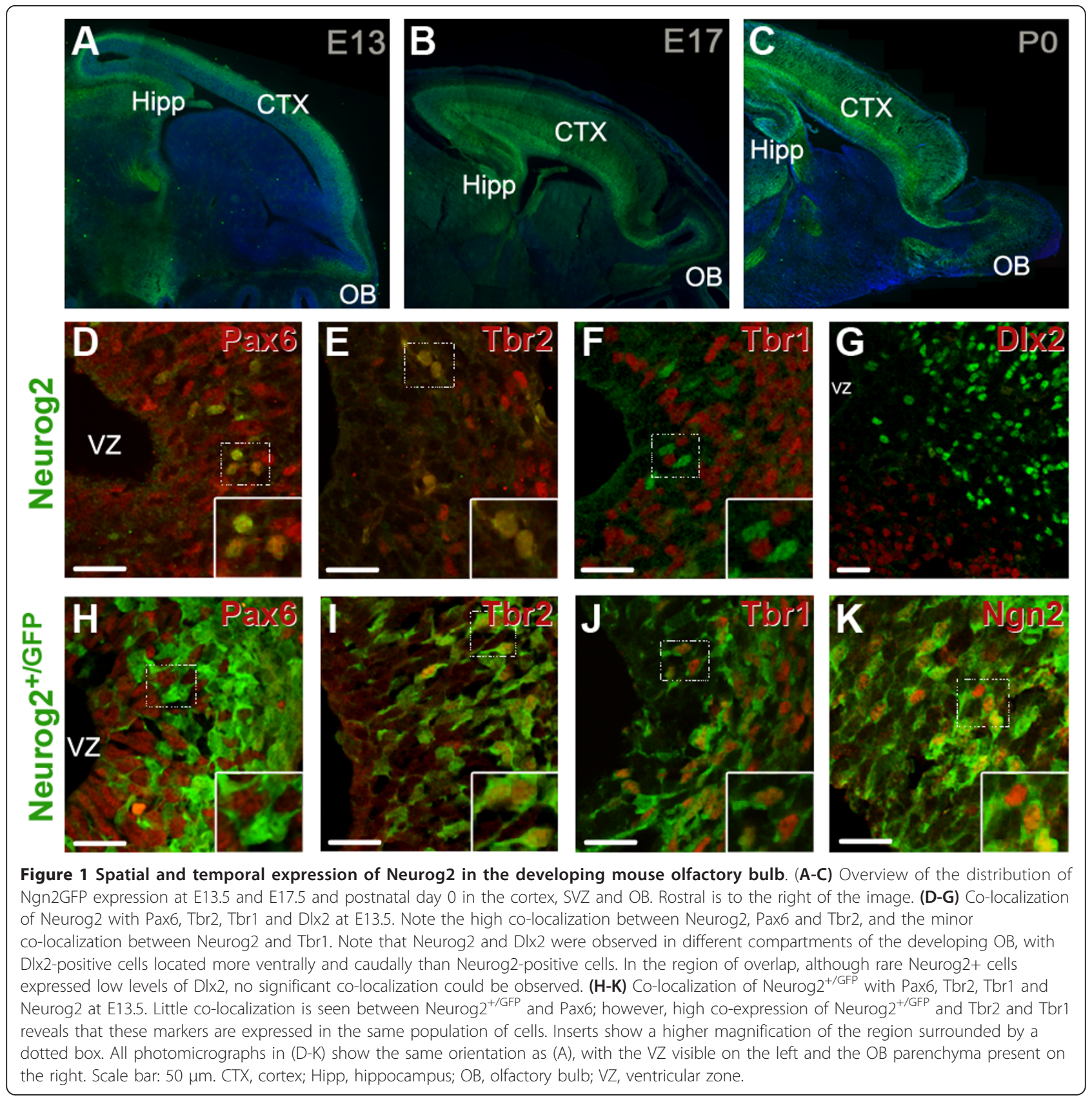

to the GL (Kruskal-Wallis test, $P<0.001$ ), illustrating the generation of distinct cell types by the Neurog2(+) progenitors. Cells in the MCL were the largest, with an average diameter of $15.7 \pm 0.4 \mu \mathrm{m}$ (64 cells in 3 animals), while cells in the EPL had an average diameter of $13.4 \pm 0.4 \mu \mathrm{m}$ ( 57 cells in 3 animals) and cells in the GL $11.3 \pm 0.5 \mu \mathrm{m}$ (33 cells in 3 animals). The large $\operatorname{GFP}(+)$ cells in the MCL and EPL projected an apical dendrite to form a dendritic tuft in the GL. Secondary dendrites were present in the EPL running parallel to the MCL and axonal projection could often be seen leading towards the interior of the $\mathrm{OB}$, presumed to be projecting out of the bulb, to cortical areas. These anatomical features define mitral cells as well as internal, middle and superficial tufted cells, the two populations of glutamatergic projection neurons of the $\mathrm{OB}$.

The distribution of $\mathrm{GFP}(+)$ cells was strikingly different when animals were induced for recombination at later time points. In E17.5-injected animals (2,233 GFP(+) cells analyzed in 4 animals), only $3.1 \pm 0.6$ and $2.3 \pm 0.8 \%$ of the $\mathrm{GFP}(+)$ cells could be seen in the MCL and EPL, respectively (Figure 2C,D). Instead, most $\mathrm{GFP}(+)$ cells 


\section{Induced at E13.5}
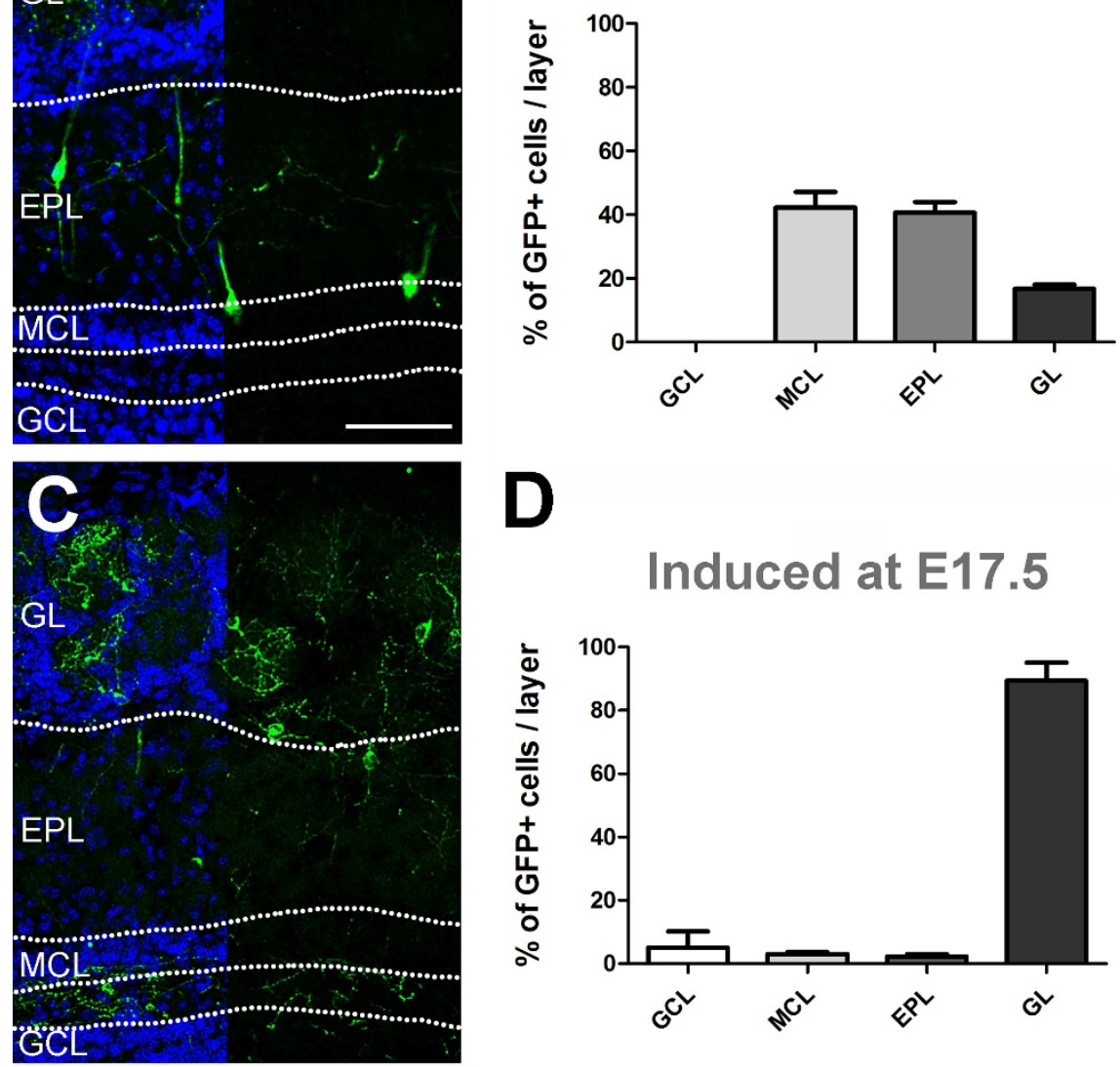

Induced at E17.5
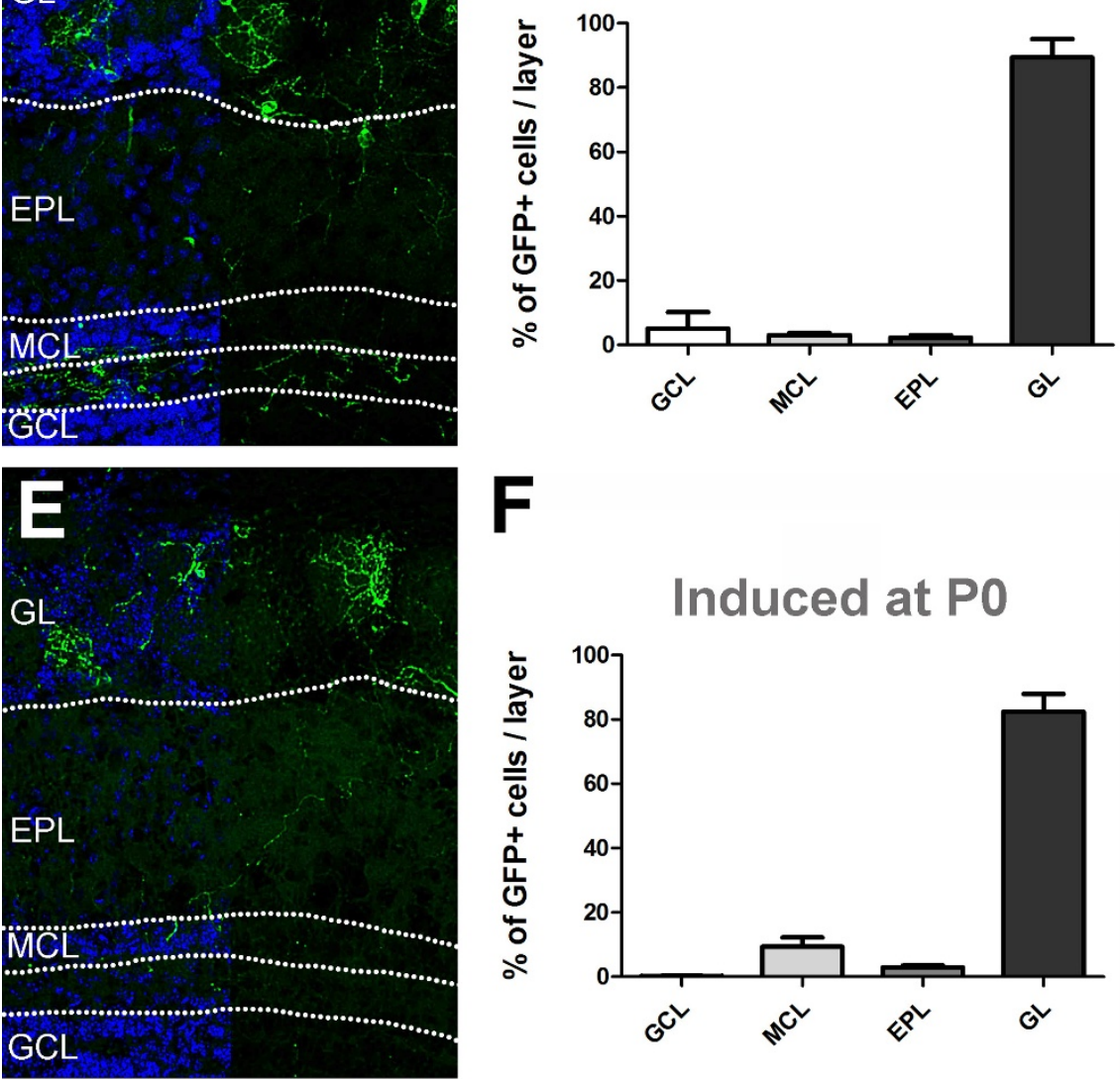

$\boldsymbol{E}$

\section{Induced at P0}

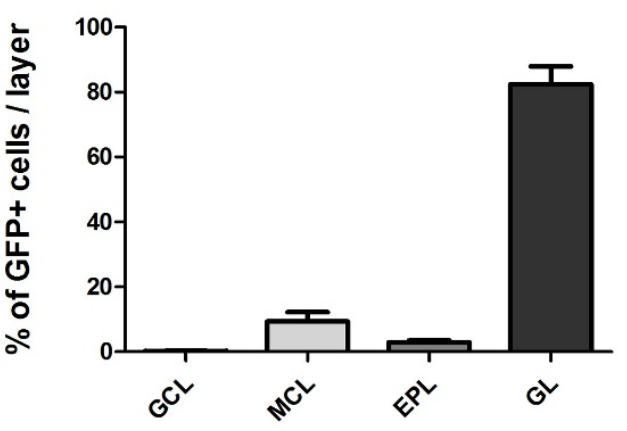

Figure 2 Neurog 2 progeny populate distinct $O B$ layers during embryonic development. (A,C,E) Overview of the distribution of GFP-positive cells in the OB of P21 Neurog2CreERT2 × TaukiGFP mice. The recombination was induced at E13.5 (A), E17.5 (C) and at birth (E) by a single injection of tamoxifen. DAPI counterstaining (blue) on the left side of the photomicrograph visualizes the distinct $O B$ layers. (B,D,F)

Quantification of the percentage of Neurog2-derived GFP-positive cells observed in the OB layers following tamoxifen injection at E13.5 (B), E17.5 (D) and at birth (F). Scale bar: $100 \mu \mathrm{m}$. EPL, external plexiform layer; GL, glomerular layer; GCL, granular cell layer; MCL, mitral cell layer. Error bars indicate S.E.M. 
were located in the GL $(89.4 \pm 5.7 \%)$. Most of these cells showed a dendritic tuft extending in a single glomerulus. Similarly, P0-injected animals $(2,011 \mathrm{GFP}(+)$ cells analyzed in 3 animals) showed a low number of cells in the MCL $(9.3 \pm 2.8 \%)$ and in the EPL $(2.9 \pm 0.6 \%)$ (Figure 2E, F). The vast majority of $\mathrm{GFP}(+)$ cells were again observed in the GL $(82.5 \pm 5.4 \%)$. Interestingly, the few cells observed in the MCL showed morphology different from mitral cells, with significantly smaller cell body diameter and poorly ramified dendrites (data not shown), suggesting the existence of a small population of Neurog2derived interneurons in these deeper OB layers.

Together, these findings show that Neurog2(+) progenitors contribute to the sequential generation of mitral and tufted cells at early developmental stages, but also to a large population of smaller diameter, predominantly juxtaglomerular neurons at later developmental stages.

\section{Expression of Tbr1, Tbr2 and HuC/D by Neurog2-derived juxtaglomerular neurons}

We went on to investigate the large population of juxtaglomerular neurons generated by Neurog2(+) progenitors. The expression of neuronal subtype markers by Neurog2(+) progenitors was assessed at P21, following tamoxifen injections at the same three time points mentioned above.

We first assessed the expression of the neuronal markers $\mathrm{NeuN}$ and $\mathrm{HuC} / \mathrm{D}$ by Neurog2-derived neurons. These two neuronal markers label two largely non-overlapping populations of neurons in the adult OB (Additional file 3). Independently of their birthdates, the juxtaglomerular Neurog2-derived neurons showed a consistent lack of NeuN expression $(0.18 \%, 2$ of $1,135 \mathrm{GFP}(+)$ cells analyzed). In clear contrast, $\mathrm{GFP}(+)$ cells were frequently seen to be $\mathrm{HuC} / \mathrm{D}$ positive $(94.5 \%, 153$ of $162 \mathrm{GFP}(+)$ cells investigated).

We next checked for expression by Neurog2-derived $\mathrm{GFP}(+)$ cells of the calcium binding proteins calretinin $(\mathrm{CR})$ and calbindin $(\mathrm{CB})$ as well as the dopamine synthesis enzyme tyrosine hydroxylase $(\mathrm{TH})$, three markers delineating distinct classes of GABAergic interneurons in the GL. No expression of CR and CB could be observed in Neurog2-derived neurons at any of the time points investigated (1,101 and 1,040 cells, respectively; Figure 3). Only two cells were seen to be positive for $\mathrm{TH}$ in one of the E17.5-injected animals $(0.17 \%, 2$ of $1,195 \mathrm{GFP}(+)$ cells analyzed). These data show that Neurog2-derived neurons do not express markers of periglomerular (PG) interneurons. Finally, we assessed the expression of the transcription factors Tbr1 and Tbr2 by the GFP(+) cells. These markers are known to label mitral and tufted cells as well as some juxtaglomerular cells $[23,24]$. In agreement with these previous findings, Tbr1 and Tbr2 immunostaining revealed a high number of positive cells in the MCL, EPL and GL (Additional file 4). Despite showing a similar distribution, we found that the staining for Tbr2 was stronger and more widespread than that of Tbr1 in the GL and EPL as revealed by counting the number of DAPI $(+)$ cells expressing the two markers throughout the OB layers (Additional file 4).

Interestingly, the expression of these two markers significantly differs in juxtaglomerular cells generated at early and late developmental time points (Figure 3). Thus, while Tbr2 stably labeled most of the Neurog2derived neurons at the three time points investigated $(100 \%$ at $\mathrm{E} 13.5,97.9 \pm 2.2 \%$ at E17.5 and $97.1 \pm 0.7 \%$ at P0; 1,158 cells analyzed in 10 animals), Tbr1 predominantly labeled late-born Neurog2-derived neurons (unpaired $t$-test, $P<0.0001)$. In E13.5 Tam-injected animals, only $1 \pm 0.96 \%$ of $\mathrm{GFP}(+)$ cells expressed Tbr 1 (6 of 347 cells investigated in 3 animals). This percentage increased to $21.9 \pm 6.5 \%$ in E17.5 Tam-injected animals (108 $\mathrm{GFP}(+)$ cells analyzed in 3 animals), with the highest proportion of co-labeling seen in P0 Taminjected animals, with $97.1 \pm 0.7 \%$ of the Neurog2derived neurons expressing Tbr1 (368 GFP(+) cells analyzed in 3 animals).

These results indicate that Neurog2-derived progeny gradually populate the GL throughout the later stages of embryogenesis, generating first a population of Tbr2positive juxtaglomerular cells (defined from here on as Tbr1(-)), followed by a second population of cells coexpressing Tbr1 and Tbr2 (defined from here on as $\operatorname{Tbr} 1(+))$.

\section{Glutamatergic nature of olfactory bulb Tbr1- and Tbr2- positive cells}

In order to confirm the glutamatergic nature of $\mathrm{Tbr} 1(+)$ and Tbr2(+) neurons, we first tested whether these cells expressed vesicular glutamate transporters (VGluTs). Given the ubiquitous nature of the amino acid glutamate, in situ hybridization for VGluTs has come to be recognized as the most reliable method to label the cell bodies of glutamatergic neurons [25]. In agreement with recent findings in the rat $\mathrm{OB}$ [26], we found that, in the mouse OB, VGluT1 and 2 showed marked differences in their distributions through the OB layers. A larger proportion of VGluT1-positive cells was observed in the mitral cell layer, as well as strong expression at the boundary of the GL and EPL. By contrast, in addition to VGluT2 expression in the MCL and EPL, a large proportion of VGluT2-positive cells was found in the GL, many found more peripherally than the VGluT1(+) expression (Additional file 5$)$. Whilst the majority of VGluT1/2(+) cells were Tbr2(+), only a smaller fraction was positive for Tbr1, confirming the smaller size of this second cell population (Figure 4A,D). 


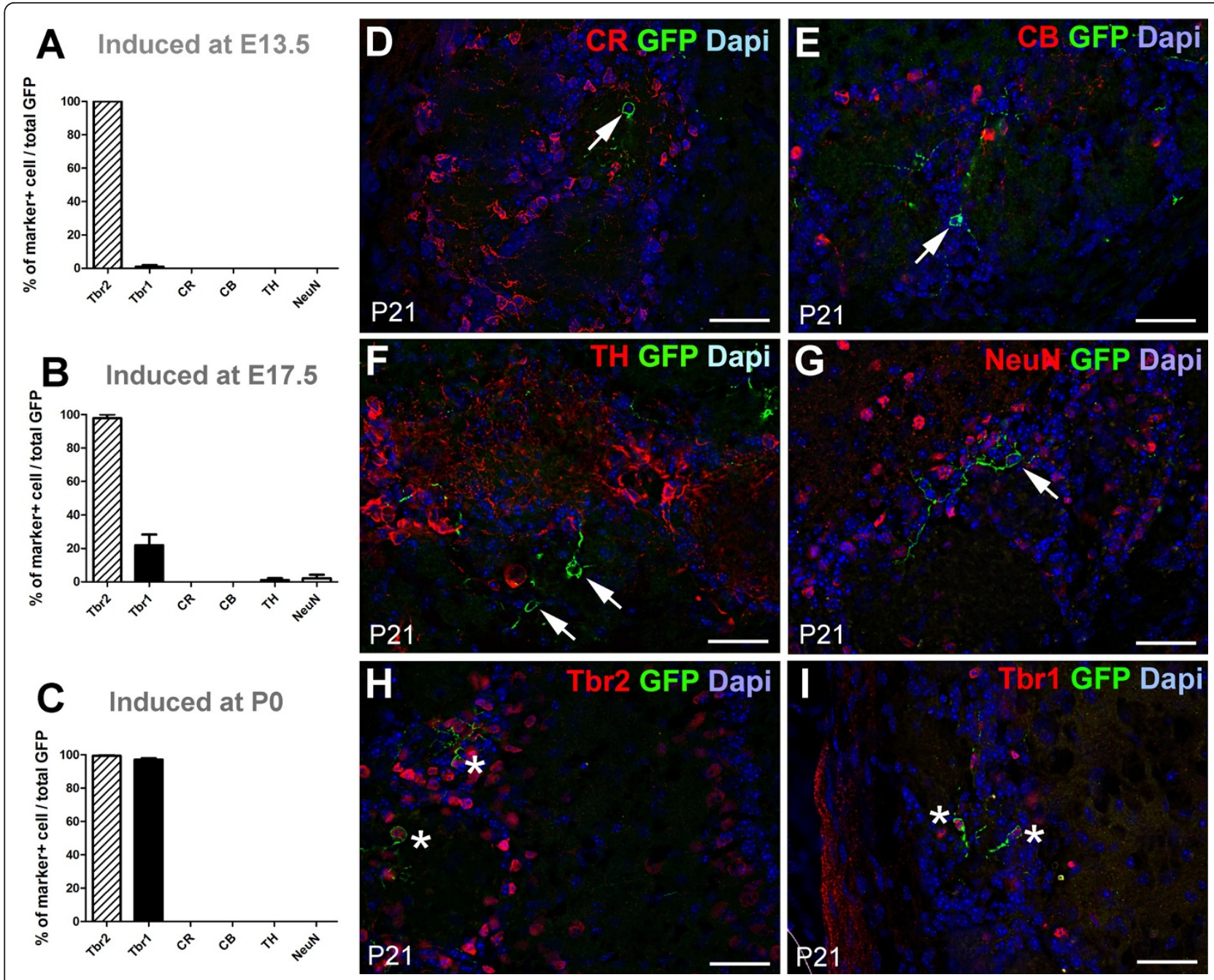

Figure $3 \mathrm{Ngn} 2$ progenitors sequentially generate Tbr2- and Tbr1-expressing neurons during embryonic development. (A-C) Antigenic properties of Neurog2-derived OB juxtaglomerular neurons of P21 Ngn2CreERT2 $\times$ TaukiGFP mice. The recombination was induced at E13.5 (A), E17.5 (C) and at birth (E) by a single injection of tamoxifen. Error bars indicate S.E.M. (D-I) High field images of the pattern of expression of the markers used to identify subpopulations of juxtaglomerular $\mathrm{OB}$ neurons. All images were acquired from animals induced at birth and sacrificed at P21. Arrows point to cells negative for the markers tested. Asterisks indicate cells positive for Tbr2 and Tbr1. Scale bar: $50 \mu m$ in all panels. $C B$, calbindin; CR, calretinin; NeuN, neuronal nuclear antigen; Tbr1 and Tbr2, T-box protein 1 and 2; TH, tyrosine hydroxylase.

To further confirm the glutamatergic nature of Tbr1and Tbr2-labeled juxtaglomerular cells, we next assessed their expression of GABAergic markers. We took advantage of the availability of knock-in GAD67-GFP mice [27]. We found no co-localization of Tbr1 and Tbr2 with GAD67-GFP (853 Tbr1 and 2,707 Tbr2 cells analyzed, respectively, in 3 animals; Figure 4B,E). The second isoform of glutamic acid decarboxylase (GAD65) was also absent in Tbr1- and Tbr2-positive cells, as visualized using an antibody specific for the GAD65 isoform [28]. Again, we found no overlap of Tbr1 or Tbr2 with GAD65 (135 Tbr1 and 978 Tbr2 cells analyzed, respectively, in 3 animals; Figure 4C,F), strongly suggesting an exclusive glutamatergic nature of Tbr1- and
Tbr2-positive juxtaglomerular cells. Finally, we assessed the co-localization of the GABAergic markers CR, CB and parvalbumin, and the dopaminergic neuron marker $\mathrm{TH}$. There has been much debate about the possible non-GABAergic nature of some CB and CR PG cells due to an absence of GABA, GAD67 and GAD65 immunodetection in these cells [29-31], although this seems to be predominantly due to efficiency of staining techniques [32]. Interestingly, we found no co-expression of Tbr2 or Tbr1 with parvalbumin (not shown) or CR, CB, and TH (Figure 4G-L; total of 397, 1,223, 1,663 and 898 cells counted, respectively).

In summary, our data provide evidence that Tbr1 and Tbr2 are reliable markers of developmentally generated, 

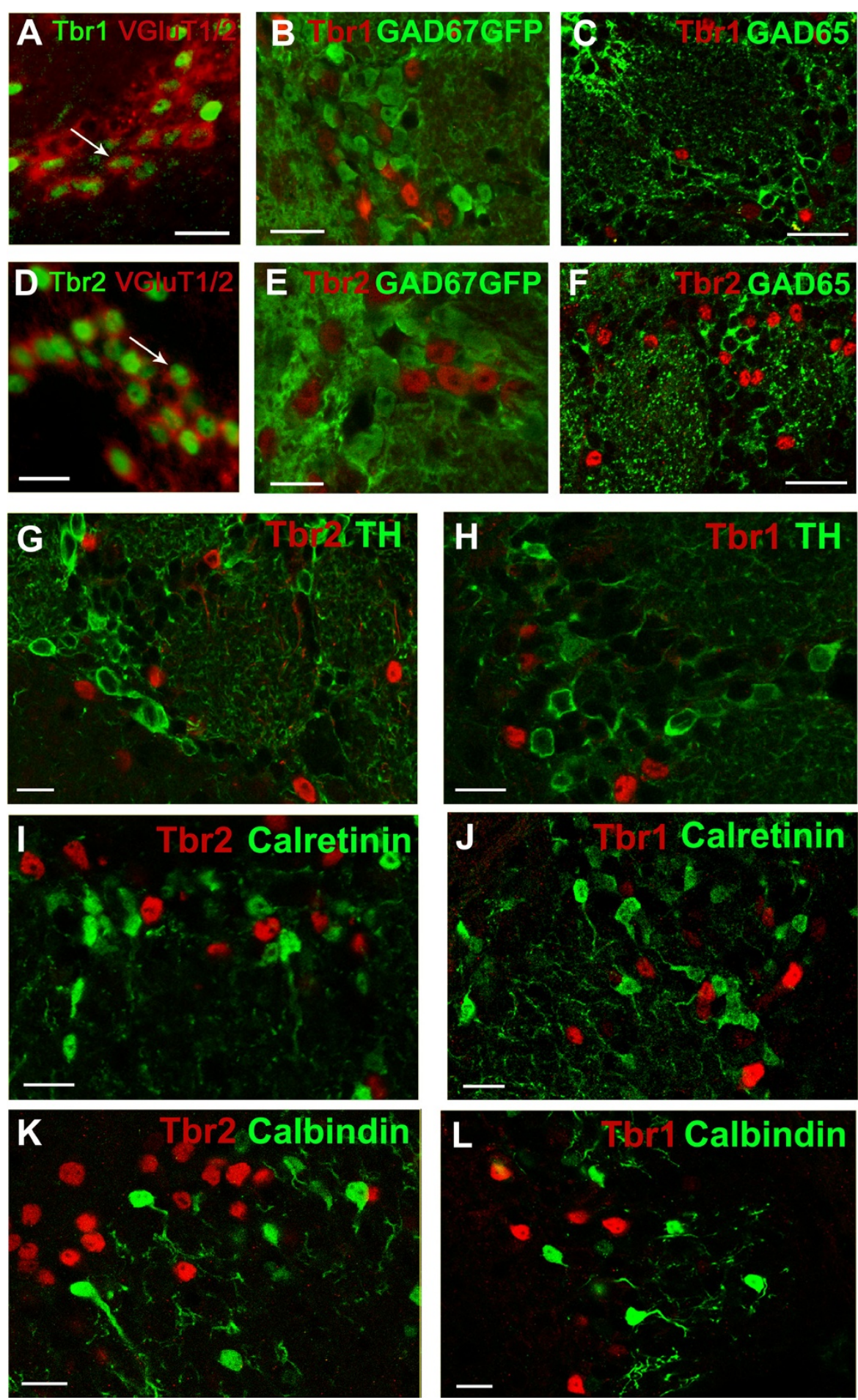

Figure 4 Glutamatergic phenotype of Tbr2- and Tbr1-positive juxtaglomerular OB neurons. (A,D) Tbr2 and Tbr1 are found in VGluTpositive cells, as revealed by combining in situ hybridization for VGluT1/2 (here imported into the red channel) and immunostaining in the green channel. Images are taken from the GL. (B,C,E,F) Tbr2 and Tbr1 do not co-localize with GAD67-GFP (B,E) nor GAD65 (C,F), confirming the non-GABAergic identity of these cell populations. Images are from the GL. (G-L) Tbr2 and Tbr1 do not co-localize with known periglomerular cell markers ( $T H, C R, C B$ or parvalbumin) in the GCL. Scale bars: $50 \mu \mathrm{m}$ in (A-D); $20 \mu \mathrm{m}$ in (G-R). 
Neurog2-derived glutamatergic neurons throughout OB layers, in contrast to adult born glutamatergic neurons that do not express these two markers [10]. Moreover, our results suggest that whereas most Neurog2-derived glutamatergic neurons generated during development express Tbr2, a smaller population also expresses Tbr1, which might therefore represent a marker of a subpopulation of juxtaglomerular glutamatergic neurons.

\section{Differential expression of Tbr1 by external tufted} interneurons and short axon cells in the glomerular layer We next investigated further the nature of Tbr1(+) neurons by performing morphometric analysis of individually reconstructed juxtaglomerular neurons. Two populations of juxtaglomerular cells have been proposed to be glutamatergic: the external tufted cells and a subpopulation of short axon cells. These two cell populations can be classified according to their morphology [33]. External tufted cells most often show a single apical dendrite that ramifies into a single glomerulus while short-axon cells show multiple, sparsely branched dendrites that project predominantly in the GL [33].

Beside their antigenic heterogeneity, the morphology of the GFP(+) cells born at E17.5 and P0 appeared to be very different, with most cells showing dendrites filling up nearby glomeruli at the earlier time point, whereas, a large number of the P0-generated cells showed clear PG dendritic arborization (Figure 5A,B). These pronounced differences in dendritic arborizations were clearly visible between Neurog2-derived Tbr1(+) and Tbr1(-) juxtaglomerular neurons born at P0 (Figure 5C-G). The dendritic arborization of randomly selected $\mathrm{GFP}(+)$ cells was reconstructed by performing neurolucida drawing from confocal stacks (14 Tbr1(+) cells and 16 Tbr1(-) cells). Tbr1(+) cells showed small dendritic arbors when compared to the Tbr1(-) cells $(272.9 \pm 20.4 \mu \mathrm{m}$ compared to $569.2 \pm 45.7 \mu \mathrm{m}$; unpaired t-test, $P<0.01$; Figure $5 \mathrm{H}$ ), reflecting the more compact dendritic arborization of Tbr1(-) cells that could more readily be observed on a single tissue section. The branching ratio was not, however, significantly different between $\mathrm{Tbr} 1(+)$ and Tbr1(-) cells $(7.2 \pm 0.8$ versus $5.6 \pm 0.8$; unpaired $t$-test, $P>$ 0.05 ; Figure 5I). Sholl analysis of the two populations of cells also underlined major morphological differences, with Tbr1(-) cells showing a unipolar tufted morphology while the majority of Tbr1(+) cells showed multipolar morphologies, as reflected by the higher number of intersections close to the cell body. More distally, the Tbr1(+) cells showed fewer ramifications, resulting in a smaller and more stable number of intersections at increasing distances (Figure 6C). Finally, there were clear differences in the intraglomerular versus PG location of the dendritic arborizations of Tbr1(+) and Tbr1
(-) cells. Thus, while most Tbr1(-) cells showed clear intraglomerular dendritic arborization, with $97.4 \%$ of the dendrites branching inside a single glomerulus (Figure 6A,D), Tbr1(+) cells showed primarily a PG dendritic arborization, with only $23.8 \%$ of their dendrites penetrating glomeruli (Figure 6B,D).

All together, these anatomical features identify Tbr1 (+) cells as short axon cells, while Tbr1(-) cells are external tufted cells. These two populations of glutamatergic neurons derive from Neurog2-expressing progenitors and are generated at different embryonic stages, with the birth of external tufted cells preceding that of short axon cells.

\section{Extrabulbar origin of some Neurog2-derived juxtaglomerular cells at perinatal ages}

We went on to assess the origin of the late generated Neurog2-derived neurons. As shown in Figure 1, the pattern of Neurog2 expression changes significantly over time, with Neurog2-positive cells being visible in more caudal ventricular regions at E17.5 and P0. Immunodetection of Neurog2 revealed that a significant proportion of the cells expressing Neurog2 at this time are found in or right below the dense layer of DAPI-positive cells lining the lateral ventricle (Figure 7A,B), suggesting that at least some cells born at this late time point arise from the lateral ventricle and migrate through the RMS to the $\mathrm{OB}$ region. Interestingly, while Neurog2(+) cells could be observed in the dorsal and hippocampal subregions of the lateral ventricles, no cells could be observed in the lateral walls.

In the dorsal aspect of the lateral ventricles, Neurog2 (+) progenitors show the same transcriptional profile observed in the OB ventricle at E13.5, with most Neurog2(+) cells co-expressing Tbr2 (Figure 7C). In order to confirm the contribution of the dorsal SVZ to OB interneurons perinatally, GFP plasmids were electroporated into the dorsal or lateral SVZ of P1 mice (Figure 7D,E). Shortly after electroporation (that is, 48 hours), GFP(+) cells were only observed in the dorsal (Additional file 6) or lateral walls of the lateral ventricle. No GFP $(+)$ cells were observed at this early time point in the RMS or OB, excluding the possibility of direct labeling of intrabulbar progenitors (Additional file 6). At 12 days post-electroporation, many GFP-expressing cells could be detected throughout the $\mathrm{OB}$. In the dorsally electroporated animals $(n=4)$, out of $342 \mathrm{GFP}(+)$ cells seen in the GL, we identified 5 that unmistakably co-localized with Tbr2 (Figure 7F,G). However, no co-localization with Tbr2 was found in the laterally electroporated animals $(n=3 ; 241$ $\mathrm{GFP}(+)$ cells analyzed).

These results indicate that cells born in the dorsal region of the perinatal SVZ migrate to the OB and mature to 

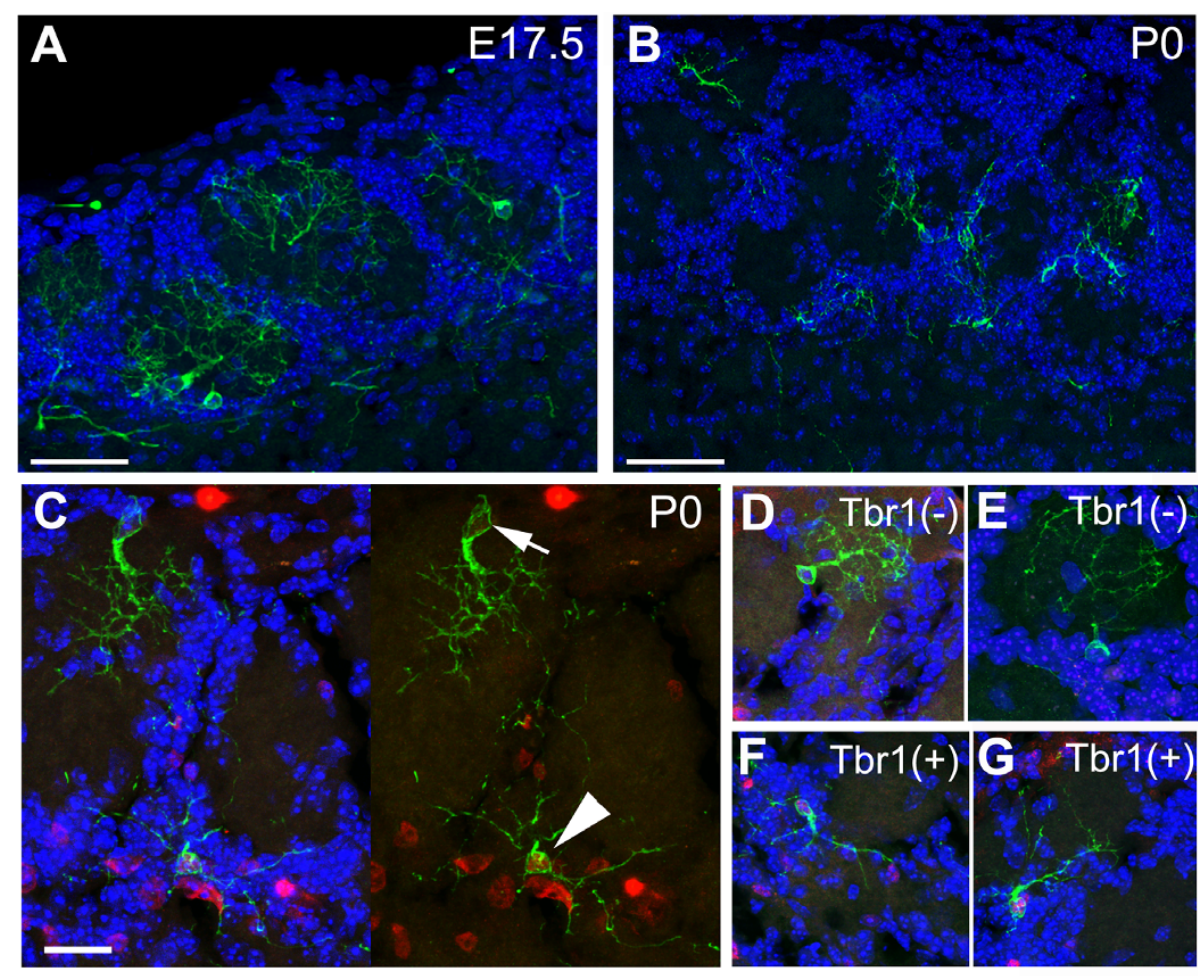

\section{H}
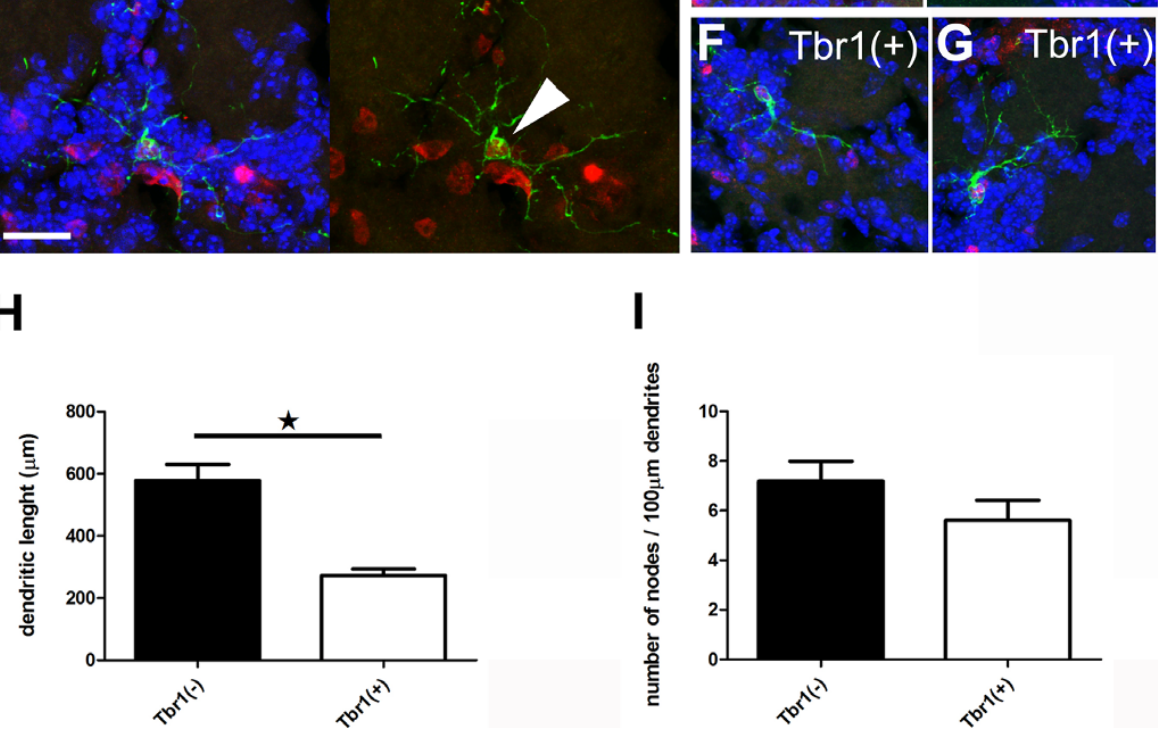

Figure 5 Neurog2 progenitors generate juxtaglomerular neurons with distinct morphologies at E17.5 and P0. (A,B) Maximal intensity projection of Neurog2-derived juxtaglomeular neurons generated at E17.5 (A) and P0 (B). Note the distinct morphology of the neurons generated at the two time points. While most neurons generated at earlier embryonic time points present intraglomerular dendritic arborization, those generated at birth show periglomerular dendritic arborization. (C) Maximal intensity projection of Tbr1-positive (arrowhead) and Tbr1negative (arrow) neurons. (D-G) Other illustrative examples of maximal intensity projection showing the dendritic arborization of Tbr1-negative $(\mathrm{D}, \mathrm{E})$ and Tbr1-positive (F-G) neurons. $(\mathbf{H}, \mathrm{I})$ Tbr1 immunoreactivity identifies juxtaglomerular neurons with distinct morphologies as illustrated by the smaller dendritic arbor $(\mathrm{H})$, while no differences in their branching ratio could be observed (I). Scale bars: $50 \mu \mathrm{m}$ in (A-C); $10 \mu \mathrm{m}$ in (C-F). Error bars indicate S.E.M.; $* P<0.05$, determined by unpaired t-test.

form glutamatergic neurons. A small population of $O B$ glutamatergic neurons therefore has an extrabulbar origin during $\mathrm{OB}$ development.

\section{Discussion}

OB development, in a similar manner to cortical development, has traditionally been thought to occur in two phases. The first stage concerns the production of glutamatergic projection neurons, which are born in the VZ and migrate radially into the $\mathrm{OB}$. In the second stage,
GABAergic interneurons arrive from extrabulbar origins (that is, first from the lateral ganglionic eminence and then from the postnatal RMS and lateral ventricle SVZ). In this study we show that there is considerable overlap between these two stages, with a significant number of glutamatergic $\mathrm{OB}$ neurons continuing to be born up to perinatal ages. Our results show the existence of a large population of intrabulbar Neurog2(+) progenitors at early developmental stages, when OB projection neurons are produced. At later stages, juxtaglomerular glutamatergic 

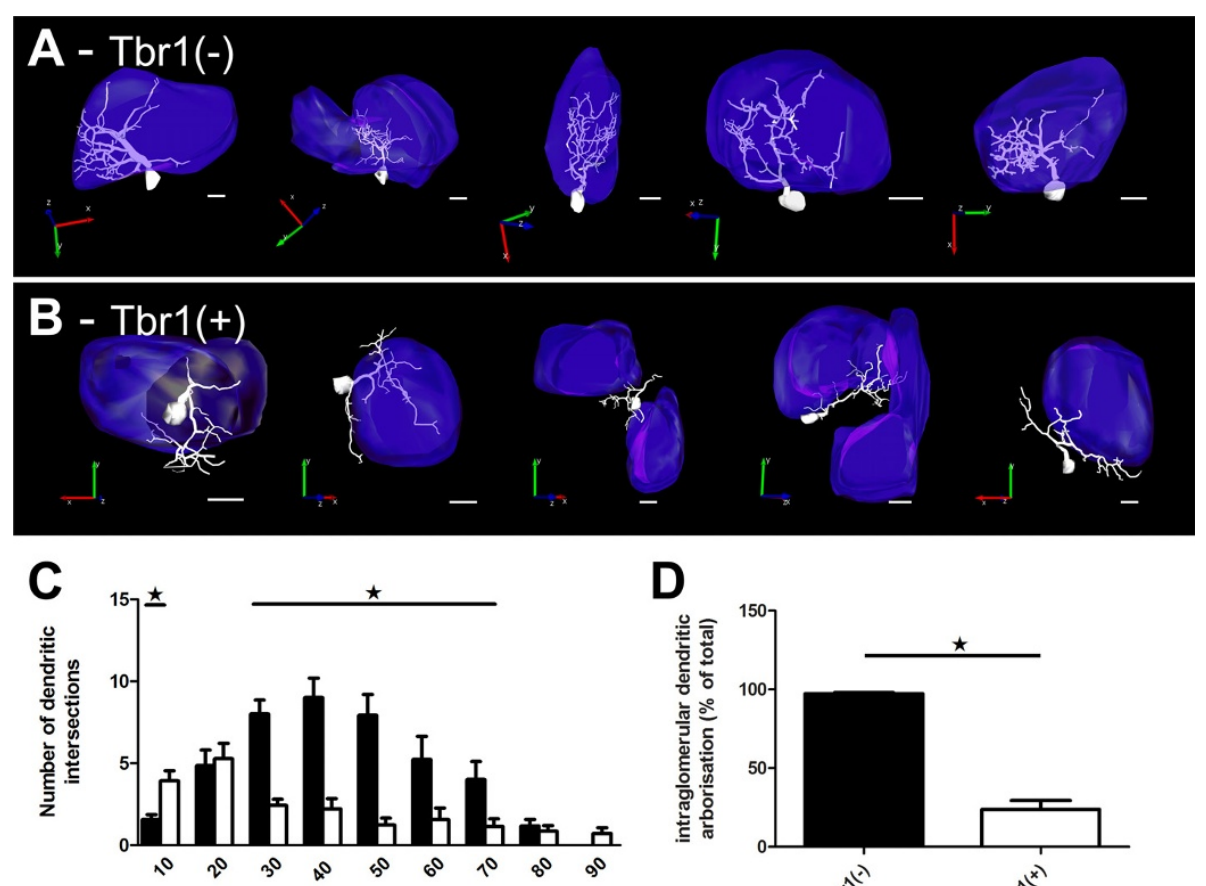

distance from cell body $(\mu \mathrm{m})$

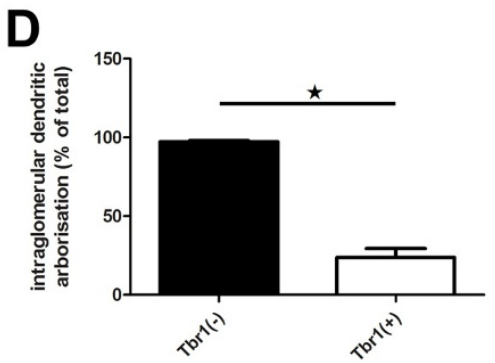

Figure 6 Tbr1 immunoreactivity distinguishes short axon cells from surrounding tufted juxtaglomerular interneurons. (A,B) Neurolucida reconstruction of individual Neurog2-derived juxtaglomerular neurons and of the associated glomeruli that are negative (A) or positive (B) for Tbr1. A three-dimensional drawing of individual glomeruli is shown in blue. (C) Sholl analysis of the two populations of cells reveals a tufted arborization of the Tbr1-negative population of juxtaglomerular cells. (D) Quantification of the percentage of intrabulbar dendritic arborization. Note the very pronounced differences observed between the two cell populations, with Tbr1-negative juxtaglomerular neurons showing intraglomerular extending dendrites while Tbr1-positive neurons show preferential periglomerular dendrites. Scale bars: $20 \mu m$ in (A); $15 \mu m$ in (B-E); $10 \mu \mathrm{m}$ in $(F, G)$. Error bars indicate S.E.M.; ${ }^{*} \mathrm{P}<0.05$, determined by unpaired t-test.

interneurons - that is, external tufted cells and short axon cells - are sequentially produced by progenitors from both intrabulbar and extrabulbar origins.

The decision to differentiate into a glutamatergic versus GABAergic neuronal phenotype is a binary fate choice in the developing telencephalon. Forebrain glutamatergic neurons have a pallial origin while GABAergic neurons are of subpallial origin. Several studies have demonstrated the central role of the proneural bHLH proteins Neurog2 and Mash1 in specifying these two classes of neurons $[14,34,35]$. In agreement with these studies, our fate mapping study confirms the exclusive glutamatergic fate of Neurog2-expressing progenitors in the developing OB. Our immunostaining experiments reveal that, at all time points investigated, Neurog2 is part of a transcriptional cascade comprising Pax6, Tbr2 and Tbr1. This transcriptional cascade, previously observed in the developing neocortex [11] and in the adult dentate gyrus [36], has been proposed to represent a generic program in the specification of glutamatergic neurons [12]. As illustrated here, however, the glutamatergic neuron subtypes produced at different developmental stages differ greatly in their morphology, pattern of projection and possibly electrophysiological properties. Thus, while large projection neurons are produced at early embryonic stages, smaller juxtaglomerular neurons are produced at later stages. These juxtaglomerular neurons show marked differences in their morphologies, with the dendritic arborization of late-born neurons becoming restricted to the GL. The nature of the signals determining the acquisition of these distinct cellular fates remains unknown. As in the neocortex, it is likely that diverse transcription factors act in concert with the generic glutamatergic transcriptional program discussed above to generate this diversity [37]. Alternatively, external constraints, such as the gradual development of the dense innervation in the glomeruli by neurons from the olfactory epithelium, may prevent dendritic growth inside glomeruli at late developmental stages. Interestingly, such PG dendritic arborizations are observed in all postnatal and adult-born subclasses (that is, GABAergic and glutamatergic) of adult-born OB interneurons [10,38].

Our results show that none of the Neurog2-derived juxtaglomerular neurons express classical markers of GABAergic PG neurons (that is, CR, CB, TH and parvalbumin). Instead, we show that all Neurog2-derived 


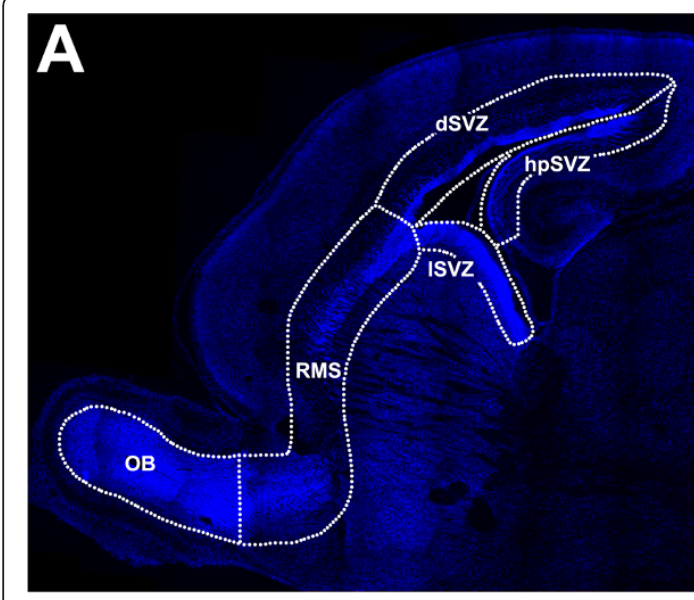

\section{Pax6}

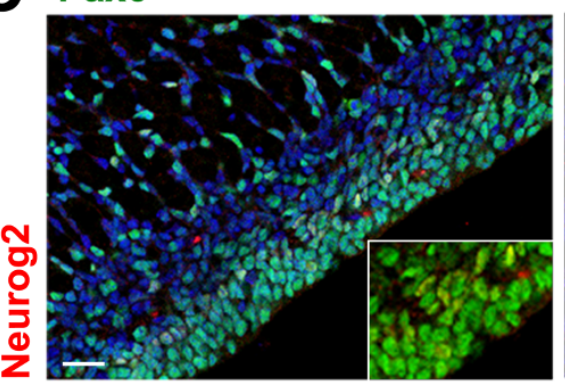

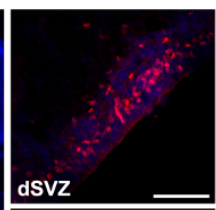

Tbr2
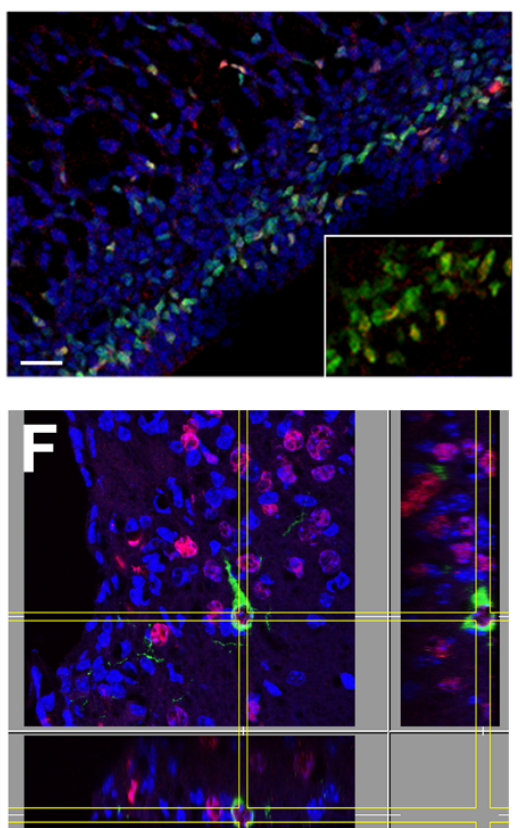

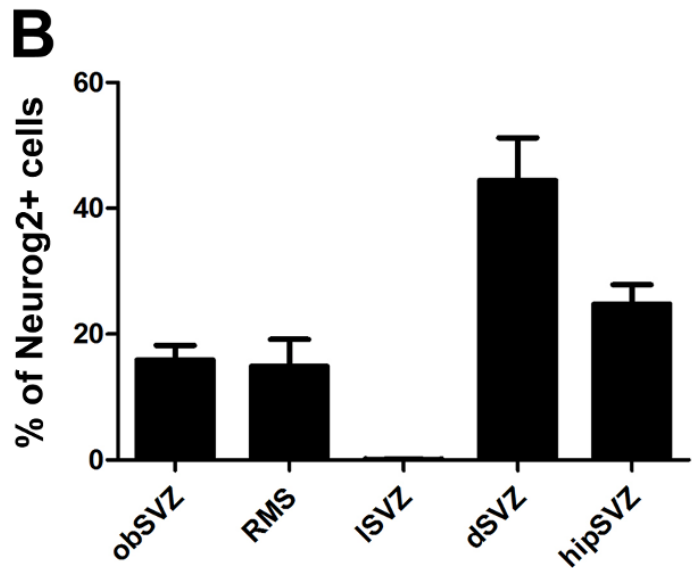

Tbr1
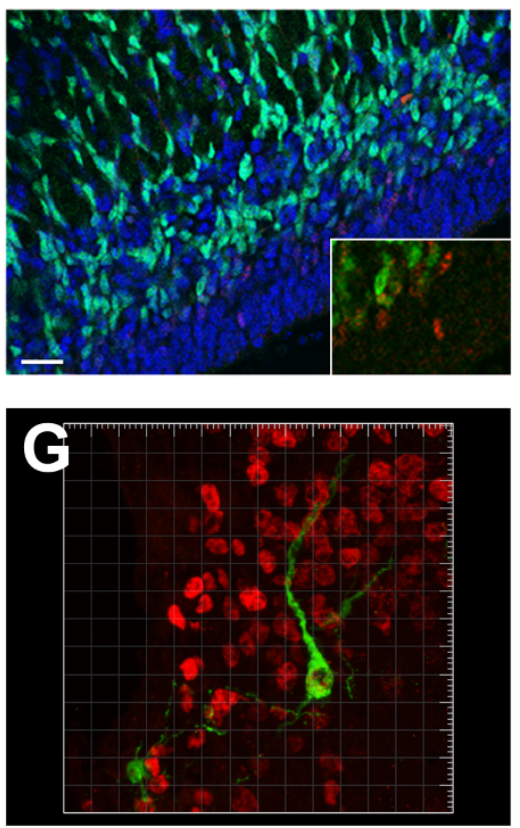

Figure 7 Some glutamatergic periglomerular interneurons are of extrabulbar origin at perinatal ages. (A,B) Distribution of Neurog2 protein throughout the SVZ, RMS and OB. (A) The PO forebrain SVZ divided into five areas: olfactory bulb SVZ (obSVZ); RMS, also containing the more rostral portion of the lateral ventricle; lateral SVZ (ISVZ); dorsal SVZ (dSVZ, also named subcallosal SVZ); and hippocampal SVZ (hpSVZ). (B) The percentage of Neurog2-positive cells found in each area in a 40- $\mu \mathrm{m}$ thick sagital section from three independent animals. Error bars indicate S.E.M. (C) Co-staining of Neurog2 protein with Pax6, Tbr2 and Tbr1 showing a similar sequential expression of the four markers as observed at earlier developmental stages in the OB. Neurog2 protein shows a strong co-localization with Pax6 and Tbr2, but is down-regulated before Tbr1 expression. (D-G) GFP(+) cells arising from the dorsal SVZ give rise to some Tbr2-expressing juxtaglomerular OB neurons. Electroporation at birth of a GFP plasmid in the lateral (D) and dorsal (E) walls of the lateral ventricles at birth. (F,G) Only the dorsal electroporated animals show some Tbr2-positive juxtaglomerular neurons 12 days later, illustrating the extrabulbar origin of some OB glutamatergic juxtaglomerular neurons. Scale bars: $100 \mu \mathrm{m}$ in (A, inserts); $20 \mu \mathrm{m}$ in (C).

cells are positive for the T-box protein Tbr2, while some also express Tbr1. These two proteins represent reliable markers of developmentally born OB glutamatergic neurons as demonstrated by in situ hybridization for VGlut1 and 2, and confirmed by the lack of coexpression with the GABAergic markers GAD67 and GAD65. The absence of $\mathrm{CR}(+)$ PG neurons in the
Neurog2 progeny is of particular interest. There has been much debate about the possible non-GABAergic nature of a large fraction of $\mathrm{CR}(+)$ PG neurons due to an absence of GABA, GAD67 and GAD65 immunodetection in these cells [29-31], although this seems to be predominantly due to efficiency of staining techniques [32]. Our results suggest that the vast majority of 
VGlut1/2 positive cells are Tbr $1 / 2$ positive, and argue against the existence of a large number of $\mathrm{CR}(+)$ glutamatergic neurons.

The absence of $\mathrm{TH}(+)$ PG neurons in the Neurog2 progeny is also of significance. Previous work has shown a role for Neurog2 in the generation of dopaminergic neurons in the midbrain $[39,40]$. In contrast, our fate mapping analysis shows only two Neurog2-derived PG neurons expressing the dopaminergic marker $\mathrm{TH}$ (representing $<0.2 \%$ of the Neurog 2 progeny) in the developing OB. Interestingly, previous studies have shown an involvement of Pax6 in the generation of PG dopaminergic neurons during development as well as in adulthood [41-44]. Considering the significant degree of overlap of Pax6 and Neurog2 in the developing forebrain, as well as in the dorsal aspect of the lateral ventricle at later stages, it might appear surprising that more $\mathrm{TH}(+)$ neurons were not observed in the Neurog2 progeny. Thus, during development, $\mathrm{TH}(+) \mathrm{OB}$ interneurons might originate exclusively from the dorsal lateral ganglionic eminence where Pax6 expression overlaps with Mash1, but where Neurog2 expression is absent $[45,46]$. Alternatively, it is possible that several populations of pallial progenitors expressing different levels of Neurog2 co-exist, with our Cre-lox approach preferentially targeting cells expressing high levels of Neurog2. Pax6 is known to regulate Neurog2 directly, in a concentration-dependent manner [47], making the existence of a Pax6/Neurog $2^{\mathrm{HIGH}}$ and a Pax6/ Neurog $2^{\mathrm{LOW}}$ population of pallial progenitors conceivable. In such a model, the level of expression of Neurog2 might represent a switch in GABAergic/glutamatergic fate acquisition of $O B$ juxtaglomerular neurons, and explain the involvement of pallial progenitors expressing Emx1 in OB GABAergic neurogenesis [48]. A detailed analysis of the Neurog ${ }^{\text {GFP/GFP }}$ mouse (that is, Neurog2 knock-out) will be necessary to further explore this interesting possibility.

Similarly to findings challenging the exclusive extrabulbar origin of OB GABAergic interneurons [3], our findings also challenge the idea of an exclusive intrabulbar origin of glutamatergic OB neurons. Both the pattern of GFP expression in the forebrain of Neurog $2^{+/ G F P}$ and the quantification of Neurog2-expressing cells in neonatal animals illustrate the widespread distribution of these cells from the OB to more caudal areas (that are, RMS and lateral ventricles), which contribute to $\mathrm{OB}$ neurogenesis at late developmental stages. To confirm the extrabulbar origin of some Neurog2-derived neurons, we used electroporation of GFP plasmids into radial astrocytes of the lateral ventricle of newborn mice [49]. We modified this technique to specifically target subregions of the lateral ventricle (MF and OR, manuscript in press). In agreement with the exclusive dorsal location of Neurog2 $(+)$ cells, only the dorsal electroporation resulted in the successful labeling of OB neurons expressing Tbr2 after
12 days, confirming the extrabulbar origin of some of these neurons. The exclusion of GABAergic markers and the expression of VGlut $1 / 2$ by Tbr2(+) cells in the adult animal support the glutamatergic nature of these neurons. It is to be noted that the number of Tbr2 juxtaglomerular cells found originating from the lateral ventricle was low, but this number was probably an underestimation. First, the electroporation was very local, with only a fraction of the radial glia being electroporated. Second, a large number of Neurog2(+) progenitors can be seen at $\mathrm{P0}$ in the RMS, a population of progenitors that was not targeted by the electroporation. Finally, some Neurog2derived glutamatergic neurons generated at birth might not express $\mathrm{Tbr} 1 / 2$, as previously shown for most glutamatergic neurons generated in 2-month-old mice [10]. Whilst our results clearly show the extrabulbar origin of a population of glutamatergic juxtaglomerular cells, the above approaches do not yet allow us to determine the size of this population.

Of particular interest is the differential expression of Tbr1 in the two populations of juxtaglomerular glutamatergic interneurons. Based on morphological criteria, our results suggest that Tbr2 is a pan-glutamatergic marker for embryonic generated $O B$ neurons, while it does not label adult generated glutamatergic OB interneurons [10], and Tbr1 preferentially labels short axon cells and is excluded from external tufted cells. The term 'external tufted cell' has recently been applied only to tufted cells found in the GL, while those in the EPL are referred to as superficial, middle or internal tufted cells, dependent on the position of the cell body [50]. External tufted cells, whilst they have an intraglomerular dendritic tuft that appears very similar to that of other tufted cells, are not thought to project out of the OB, but rather to other areas of the GL [20,51]. Superficial short-axon cells by contrast have no dendritic tuft but are long range interneurons, projecting sparsely branching dendrites through the GL to contact distant glomeruli [33]. Our three-dimensional reconstruction of single Tbr1(-) and Tbr1(+) cells supports the classification of these cells in these two categories. Importantly, the lack of $\mathrm{TH}$ expression by $\mathrm{Tbr} 1(+)$ cells distinguishes them from other interglomerular GABAergic neurons recently described in the mouse GL $[52,53]$. The expression of Tbr2 in most $\mathrm{OB}$ glutamatergic neurons contrasts with the cortex, where only Tbr1 expression is observed in mature excitatory neurons, while Tbr2 is absent [23]. The reasons for this molecular, area-specific heterogeneity, as well as the function of the expression of these transcription factors in populations of mature glutamatergic neurons, are at present unknown.

\section{Conclusions}

Our results demonstrate the sequential generation by Neurog2(+) progenitors of distinct populations of OB 
glutamatergic neurons (Figure 8). The description of this developmental timeframe together with the use of the Neurog2iCreERT2 mice will allow future studies aimed at studying the physiology of these glutamatergic neuron subtypes, in particular of juxtaglomeurular neurons, whose exact role in olfactory processing remains to be explored $[17,18]$.

\section{Materials and methods}

\section{Animals}

Electroporation experiments were performed in agreement with the Canton of Zurich veterinary office guidelines. All other experiments were done in agreement with the United Kingdom Animals Act 1986 for scientific procedures.

Heterozygous Neurog $2^{+/ G F P}$ mice with an enhanced GFP cassette knocked-in the Neurogenin-2 locus [54]. Neurog2iCreERT2 mice were generated using a BAC encoding $i$ CreERT2 under the control of the Neurog2 promoter. The BAC was injected into blastocysts that were implanted in pseudo-pregnant females. The resulting mice were tested by PCR for the presence of the transgene. When crossed with the appropriate reporter line (RosaYFP or TauGFP) and induced with tamoxifen, the reporter is expressed in a pattern that is consistent with Neurog2 endogenous expression in the mouse brain. RosaYFP mice are homozygous reporter mice carrying the yellow fluorescent protein $(Y F P)$ transgene inserted in the Rosa26 locus [55]. TauGFP mice are homozygous Cre-reporter mice carrying the GFP transgene inserted in the neuron-specific Tau locus [22]; in this mouse, a membrane bound-GFP, consisting of a fusion of GFP with a plasmalemmal targeting sequence of the protein MARCKS [56], was expressed upon recombination. This allowed the visualization of the entire morphology of the recombinated cells.

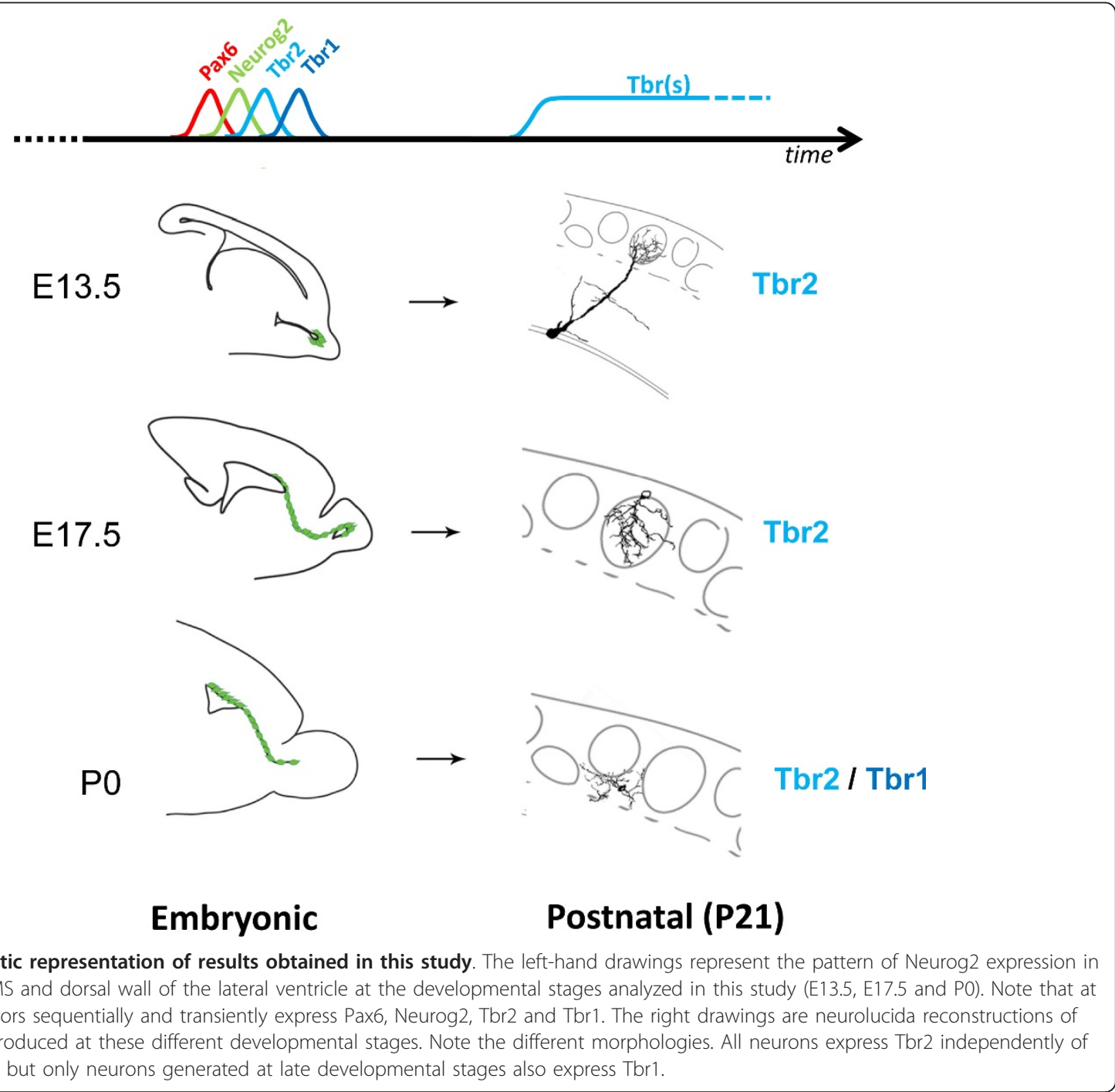


Genotyping of all transgenic strains was performed by PCR. Genotyping of the Neurog2GFP mice used 5'-3' primer GGA CAT TCC CGG ACA CAC A C and 3'-5' primer GCA TCA CCT TCA CCC TCT CC with 35 cycles of $94^{\circ} \mathrm{C} / 1$ minute, $60^{\circ} \mathrm{C} / 1$ minute and $72^{\circ} \mathrm{C} / 1$ minute to detect the knock-in form, and $5^{\prime}-3^{\prime}$ primer GAC ATT CCC GGA CAC ACA C and 3'-5' primer GAG CGC CCA GAT GTA ATT GT with 35 cycles of $94^{\circ} \mathrm{C} / 30 \mathrm{~s}, 62^{\circ} \mathrm{C} / 1$ minute and $72^{\circ} \mathrm{C} / 1$ minute were used to detect the wild-type Neurog 2 gene. To detect the knock-in of Cre recombinase in the Neurog2iCreERT2 mice, 5'-3' primer AGA TGC CAG GAC ATC AGG AAC CTG and 3'-5' primer ATC AGC CAC ACC AGA CAC AGA GAT were used with 35 cycles of $94^{\circ} \mathrm{C} / 30 \mathrm{~s}$, $62^{\circ} \mathrm{C} / 1$ minute and $72^{\circ} \mathrm{C} / 1$ minute. Genotyping of the TauGFP reporter mice used 5' -3 ' primer AAG TTC ATC TGC ACC ACC G and 3'-5' primer TCC TTG AAG AAG ATG GTG CG with 35 cycles of $95^{\circ} \mathrm{C} / 30 \mathrm{~s}$, $60^{\circ} \mathrm{C} / 30 \mathrm{~s}$, and $72^{\circ} \mathrm{C} / 1$ minute.

\section{Tamoxifen injections}

Pregnant Neurog2iCreERT2 females were injected intraperitoneally with $6 \mathrm{mg}$ of 4-hydroxytamoxifen (4-OHT) either on E13.5 or E17.5. Alternatively, P0 pups were injected with $0.5 \mathrm{mg}$ tamoxifen subcutaneously. The 4OHT solution was prepared by adding $1 \mathrm{ml}$ of absolute ethanol to $50 \mathrm{mg}$ of 4-OHT powder (Sigma no. H6278, St. Louis, Missouri, USA). The powder was put in a suspension by manual pipetting. Corn oil ( $4 \mathrm{ml}$; Sigma no C8267) was added to the 4-OHT suspension, and the mix was incubated at $37^{\circ} \mathrm{C}$ for approximately 90 minutes and agitated a few times. If needed, the mix was shortly incubated at $65^{\circ} \mathrm{C}$ to dissolve all the 4-OHT. Tamoxifen solution was prepared by adding $1 \mathrm{ml}$ ethanol to $200 \mathrm{mg}$ of tamoxifen. This solution was then sonicated and when all the tamoxifen had dissolved, $9 \mathrm{ml}$ of corn oil was added to obtain a $20 \mathrm{mg} / \mathrm{ml}$ solution. Tamoxifen-induced mice were perfused at age P21, 3 weeks after birth.

\section{Electroporation}

P1 mice were electroporated with GFP plasmid as described in detail elsewhere [49]. The plasmids were purified using the Qiagen EndoFree Plasmid Maxi Kit (Qiagen, no. 12362, Valencia, California, USA) according to the manufacturer's protocol. DNA was resuspended in sterile phosphate-buffered saline at a concentration of $5 \mu \mathrm{g} / \mu \mathrm{l}$, which was determined using the NanoDrop ${ }^{\circledR}$ ND-1000 UV-Spectrophotometer (NanoDrop Technologies, Wilmington, Delaware, USA).

Animals were perfused at either 2 or 12 days post-electroporation. Electroporation was performed on P1 mice of the CD1 strain (Swiss mice) using a method adapted from [49]. Pups were anesthetized by hypothermia before being placed in a stereotaxic rig. Injections were performed at the midpoint of a virtual line connecting the eye with Lambda. Injections were made using a 34G Hamilton syringe at a depth of $2.5 \mathrm{~mm}$. Correct injections were confirmed by visual inspection due to the filling of the lateral ventricle with the dark solution. Animals in which the injection had been successful were subjected to five electrical pulses $(90 \mathrm{~V}, 50 \mathrm{~ms}$, separated by 950 -ms intervals) using the CUY21 edit device (Nepagene, Chiba, Japan) and $10-\mathrm{mm}$ tweezer electrodes (CUY650P10; Nepagene) coated with conductive gel. Positioning of the electrodes on each side of the head caused transfer of the plasmids into the lateral SVZ, whereas positioning of the positive electrode more dorsally caused electroporation into the dorsal SVZ. Electroporated animals were warmed on a heat mat and returned to the mother.

\section{Collection of tissue}

Neurog2 $2^{+/ G F P}$ embryos were collected at E13.5 or E17.5 following an overdose of anesthetic to the pregnant female. The age of the embryos was calculated from the morning that vaginal plugs were observed, which was considered to be E0.5. Embryos were collected in dissection solution, the outer membranes removed and the entire head then fixed by immersion in $4 \%$ paraformaldehyde for 4 days, followed by cryoprotection in $30 \%$ sucrose solution. P0 and adult brains were fixed by transcardial perfusion with $4 \%$ paraformaldehyde, followed by overnight post-fixation and cryoprotection with $30 \%$ sucrose solution. OB cryosections were obtained at $40 \mu \mathrm{m}$. A minimum of three animals were used for all quantifications.

\section{Immunohistochemistry}

Sections were blocked and permeabilized with 5\% normal horse serum and $0.4 \%$ Triton X-100 in phosphate buffer for 2 hours, followed by an overnight incubation with the primary antibody dissolved in the same blocking medium. After washing, the sections were incubated for 2 hours with the corresponding secondary antibody. DAPI counterstain was performed for all stainings. The complete list of antibodies used in this study can be found in Table 1 at the end of this manuscript

Double staining was performed by applying two primary and secondary antibodies simultaneously. However, for double stainings in which the primary antibody was produced in the same animal, a more complex protocol was needed [57]. Here we first applied the first primary antibody, and used a tyramide amplification kit from Invitrogen to amplify the fluorescent signal (Invitrogen, Carlsbad, California, USA). We then microwaved the sections for 5 minutes in $10 \mathrm{mM}$ citric acid buffer, pH6, in 
Table 1 Antibodies used in this study

\begin{tabular}{|c|c|c|c|c|c|}
\hline $\begin{array}{l}\text { Target } \\
\text { protein }\end{array}$ & Antigen & Species & Dilution & Source & Antibody characterization \\
\hline GFP & $\begin{array}{l}\text { Protein isolated from } \\
\text { Aequorea victoria }\end{array}$ & Rabbit & $1: 500$ & Invitrogen & $\begin{array}{l}\text { Recognizes a single band at } 27 \mathrm{kDa} \text { on western blot of GFP } \\
\text { transgenic mouse brain. No immunostaining seen in sections not } \\
\text { containing GFP }\end{array}$ \\
\hline GFP & $\begin{array}{l}\text { Recombinant full length } \\
\text { protein }\end{array}$ & Chicken & $1: 1,000$ & $\begin{array}{l}\text { Abcam } \\
\text { ab13970 }\end{array}$ & $\begin{array}{l}\text { Recognizes a single band at } 27 \mathrm{kDa} \text { on western blot of GFP } \\
\text { transgenic mouse brain. No immunostaining seen in sections not } \\
\text { containing GFP }\end{array}$ \\
\hline Tbr2 & $\begin{array}{l}\text { Synthetic peptide from } \\
\text { mouse Tbr2 }\end{array}$ & Rabbit I & $1: 1,000$ & $\begin{array}{l}\text { Abcam } \\
\text { ab23345 }\end{array}$ & $\begin{array}{l}\text { The antibody recognizes a single band at } 72 \text { kDa on a western blot of } \\
\text { whole embryonic mouse brain (manufacturer's website). No western } \\
\text { blot staining after neutralization of antibody with Tbr2 peptide }\end{array}$ \\
\hline Tbr1 & $\begin{array}{l}\text { Synthetic peptide from } \\
\text { mouse Tbr1 }\end{array}$ & Rabbit & $1: 1,000$ & $\begin{array}{l}\text { Millipore } \\
\text { AB9616 }\end{array}$ & $\begin{array}{l}\text { The antibody recognizes the } 68 \mathrm{kDa} \text { Tbr1 protein on a western blot } \\
\text { (manufacturer's data sheet). No staining seen in Tbr1 knock-out animal } \\
\text { (manufacturer's personal communication) }\end{array}$ \\
\hline Neurog2 & $\begin{array}{l}\text { Carboxyl terminus peptide of } \\
\text { Neurogenin } 2 \text { of human } \\
\text { origin }\end{array}$ & Goat & $1: 100$ & $\begin{array}{l}\text { Santa Cruz } \\
\text { SC19233 }\end{array}$ & $\begin{array}{l}\text { No western blot staining after neutralization of antibody with } \\
\text { Neurog2 peptide }\end{array}$ \\
\hline Calretinin & $\begin{array}{l}\text { Recombinant human } \\
\text { calretinin-22k }\end{array}$ & Mouse & $1: 1,500$ & Swant 6B3 & $\begin{array}{l}\text { This antibody specifically recognizes the } 29-\mathrm{kDa} \text { band on } \\
\text { immunoblots of brain extracts. The antibody staining is absent in } \\
\text { calretinin knock-out mice (manufacturer's website) }\end{array}$ \\
\hline Calbindin & $\begin{array}{l}\text { recombinant rat calbindin D- } \\
28 \mathrm{k}\end{array}$ & Rabbit & $1: 5,000$ & $\begin{array}{l}\text { Swant } \\
\text { CB38 }\end{array}$ & $\begin{array}{l}\text { This antibody specifically recognizes the } 28-k D a \text { band on } \\
\text { immunoblots of brain extracts. The antibody staining is absent in } \\
\text { calretinin knock-out mice (manufacturer's website) }\end{array}$ \\
\hline $\begin{array}{l}\text { Tyrosine } \\
\text { hydroxylase }\end{array}$ & $\begin{array}{l}\text { Tyrosine hydroxylase purified } \\
\text { from PC12 cells }\end{array}$ & Mouse & $1: 250$ & $\begin{array}{l}\text { Millipore } \\
\text { MAB318 }\end{array}$ & $\begin{array}{l}\text { Recognizes a protein of approximately } 59 \text { to } 61 \text { kDa by western blot } \\
\text { and does not cross-react with dopamine-hydroxylase, phenylalanine } \\
\text { hydroxylase, tryptophan hydroxylase, or phenyl ethanolamine-N- } \\
\text { methyl transferase on western blots (manufacturer's website). This } \\
\text { antibody stained only cells with the typical morphology and } \\
\text { positioning of dopaminergic periglomerular cells in the olfactory bulb }\end{array}$ \\
\hline Parvalbumin & $\begin{array}{l}\text { Parvalbumin purified from } \\
\text { carp muscles }\end{array}$ & Mouse & $1: 5,000$ & $\begin{array}{l}\text { Swant } \\
\text { PV235 }\end{array}$ & $\begin{array}{l}\text { Specifically stains the } 45 \text { Ca-binding spot of parvalbumin (MW 12,000 } \\
\text { and IEF 4.9) in a two-dimensional 'immunoblot'. No antibody staining } \\
\text { seen in a parvalbumin knock-out mouse (manufacturer's website). }\end{array}$ \\
\hline Pax6 & $\begin{array}{l}\text { Peptide from the carboxyl } \\
\text { terminus of the mouse Pax6 } \\
\text { protein }\end{array}$ & Rabbit & $1: 250$ & $\begin{array}{l}\text { Covance } \\
\text { PRB-278P }\end{array}$ & $\begin{array}{l}\text { The antibody recognizes a single band at } 49 \mathrm{kDa} \text { on a western blot of } \\
\text { whole embryonic mouse brain (manufacturer's personal } \\
\text { communication) }\end{array}$ \\
\hline NeuN & $\begin{array}{l}\text { Purified cell nuclei from } \\
\text { mouse brain }\end{array}$ & Mouse & $1: 500$ & $\begin{array}{l}\text { Millipore } \\
\text { MAB377 }\end{array}$ & $\begin{array}{l}\text { Recognizes two to three bands in the } 46-\text { to } 48-\mathrm{kDa} \text { range and } \\
\text { possibly another band at approximately } 66 \mathrm{kDa} \text {. Given that NeuN is } \\
\text { defined by the antibody, it cannot be characterized. However for } \\
\text { further discussion see [58] }\end{array}$ \\
\hline HuC/D & HuC/HuD neuronal protein & Mouse & $1: 250$ & $\begin{array}{l}\text { Invitrogen } \\
\text { A-21271 }\end{array}$ & $\begin{array}{l}\text { Recognizes the Elav family members HuC, HuD and Hel-N1, which are } \\
\text { all neuronal proteins. Anti-HuC/D monoclonal } 16 \mathrm{~A} 11 \text { does not } \\
\text { recognize HuR, another Elav family member that is present in all } \\
\text { proliferating cells }\end{array}$ \\
\hline GAD65 & $\begin{array}{l}\text { Affinity-purified GAD from rat } \\
\text { brain }\end{array}$ & Mouse & $1: 1,000$ & $\begin{array}{l}\text { Abcam } \\
\text { AB26113 }\end{array}$ & $\begin{array}{l}\text { Recognizes selectively GAD65; extensively co-localizes with VGAT in } \\
\text { GABAergic axon terminals [28] }\end{array}$ \\
\hline
\end{tabular}

Swant (Marly, Fribourg, Switzerland).

Abcam (Cambridge, County of Cambridgeshire, UK).

Millipore (Billerica, Massachusetts, USA).

Santa Cruz Biotechnology (Santa Cruz, California, USA).

Invitrogen (Carlsbad, California, USA).

Covance (Princeton, New Jersey, USA).

order to denature the first primary antibody. The second primary and secondary could then be applied with no risk of cross-reaction. Appropriate controls were performed by omitting the primary antibody from the second immunoreaction. These control sections showed no signal, indicating that the secondary antibody against the second primary applied was not picking up any signal from the first primary antibody applied.

\section{Imaging}

A Leica DM6000 fluorescent microscope with a 40X/ 1.25 NA oil objective was used for cell counting. Colocalization studies and confocal images were obtained using a Leica SPE confocal laser scanning microscope with 40X/1.25 NA oil objective. Both microscopes used the Leica LAS AF software (Leica, Germany). Colocalization studies were done either by counting by 
eye from Confocal images or using the semi-automatic Imaris program (Bitplan, Zurich, $\mathrm{CH}$, Switzerland). Digital images were processed using Adobe Photoshop. Only the contrast and brightness of figures were adjusted when necessary in order to improve clarity of images.

\section{Cell reconstruction}

Three-dimensional reconstruction of individual juxtaglomerular cells and of their associated glomeruli was achieved by using the image stack module of the neurolucida software (MBF Bioscience, Williston, Vermont, USA for illustration). Sections $(50 \mu \mathrm{m})$ of the OB were immunostained for Tbr2 and Tbr1 as described above. Randomly selected cells were imaged under a confocal microscope (objective $40 \times$, NA 1.25). Image stacks encompassing the entire section thickness were collected with a z-step of $0.3 \mu \mathrm{m}$ and a minimal resolution of $1,024 \times 1,024$ pixels.

\section{In situ hybridization}

mRNA in situ hybridizations were performed on tissue fixed as for immunohistochemistry. The sections were cut to a thickness of $30 \mu \mathrm{m}$ on a cryostat and mounted directly onto Superfrost slides. Two different mRNA probes were used. The VGluT1 probe was made using RT-PCR to obtain a cDNA fragment from within the VGluT1 gene. The following primers were selective for a region from the 3' end of VGluT1, and also incorporated SP6 and T7 sequences: forward primer, TAATACGACTCACTATAGGGTTTCGGGATGGAAGCCACG; reverse primer, ATTTAGGTGACACTATAGACGTCCTCCATTTCACTTTCGTC. The $v$ GluT2 plasmid was the kind gift of Q Ma (Harvard Medical School). The probe was then made by in vitro transcription using a digoxigenin labeling kit (Roche Applied Science, Rotkreuz, Switzerland). Hybridization was done in a standard hybridization buffer, overnight at $60^{\circ} \mathrm{C}$ and the sections were then washed in decreasing concentrations of SSC before incubation for 2 hours with alkaline phosphatase-conjugated anti-digoxigenin antibody Fab fragment (Roche) diluted 1:500 in maleic acid buffer (Roche Applied Science, Rotkreuz, Switzerland). To visualize the bound phosphatase, a mixture of $3.375 \mathrm{mg} / \mathrm{ml} \mathrm{NBT}$ and 1.75 $\mathrm{mg} / \mathrm{ml} \mathrm{BCIP}$ was applied to the sections overnight, or as long as required for the reaction to develop Images were obtained using a Leica LEITZ DMRB microscope (Leica Microsystems, Heerbrugg, Switzerland) and LuciaG software (Laboratory Imaging, Praha, Czech Republic).

\section{Additional material}

Additional file 1: Figure S1: The expression of $i$ CreERT2 follows Neurog2 expression in the E14.5 mouse telencephalon. (A-D') In situ hybridization showing the expression of iCreERT2 $(A, B, C, D)$ and Ngn2 (A',
$\left.B^{\prime}, C^{\prime}, D^{\prime}\right)$ at different antero-posterior levels of the E14.5 mouse telencephalon (from anterior $\left(A, A^{\prime}\right)$ to posterior $\left(D, D^{\prime}\right)$ telencephalon. $(E, F)$ Immunodetection of Neurog2 ( $E$, top panel) and iCreERT2 (E, middle panel) in the newborn lateral ventricle reveals co-expression of the two markers in the same cells (DAPI nuclear counterstain; E, bottom panel). Note that while some cells are positive for both Neurog2 and iCreERT2 (arrow), some have downregulated Neurog2 but still express iCreERT2 (arrowhead) due to its longer half-life. Surrounding cells are consistently negative for the two markers (asterisk). Quantifications were performed by densitometry analysis (F). Grey values for DAPI, Neurog2 and iCreERT2 were measured in randomly selected $\mathrm{DAPI}(+)$ cells in the dorsal and ventral walls of the lateral ventricles of three Neurog2iCreERT2 animals ( $n>50$ cells per animal). Note the clear detection of iCreERT2 in the Neurog2(+) cell fraction. Note that iCreERT2 can also be detected in some Neurog2(-) cells, presumably cells that have downregulated Neurog2 but still express iCreERT2 due to its longer half-life.

Additional file 2: Figure S2: Short-term fate mapping of the Neurog2 progeny in the Neurog2iCreERT2 mice. Neurog2iCreERT2 mice were crossed with RosaYFP reporter mice. Animals were injected with tamoxifen at PO and scarificed 24 hours later. (A-D) Recombined cells could be observed at the transition of the lateral ventricle with the RMS (A) (the doted box on the DAPI counterstained cross-section indicates the approximate location of the GFP(+) cells shown in (B-D)). GFP immunostaining showed co-localization with Tbr2 (B) $(100 \%, n=32)$ but not with Dlx2 (C, D) $(0 \%, n=15)$, confirming the faithful expression of the Cre recombinase and the efficient labeling of the Neurog2 cell lineage.

Additional file 3: Figure S3: Neuronal phenotype of Tbr1/Tbr2positive cells. (A,B) Sequential double immunostaining for NeuN (green) and HuC/D (red) reveals different degrees of co-localization (yellow) of the two markers throughout the $\mathrm{OB}$ layers. (C) Percentage of DAPIpositive cells expressing either NeuN or HuC/D in each OB layer. (D-G) Double immunostaining of Tbr2 or Tbr1 with either NeuN or HuC/D. NeuN is excluded from the Tbr1- and Tbr2-positive cells while HuC/D preferentially labels the two $O B$ glutamatergic neuron populations. Scale bars: $100 \mu \mathrm{m}$ in (A); $20 \mu \mathrm{m}$ in (D-G).

Additional file 4: Figure S4: Distribution of Tbr1- and Tbr2-positive neurons in the mouse olfactory bulb. $(\mathbf{A}, \mathbf{B})$ Overview showing the distribution pattern of Tbr2 and Tbr1 immunoreactivity in the adult OB. (C-F) Graphs showing the quantification of the distribution of Tbr2 and Tbr1 in the different OB cell layers.

Additional file 5: Figure S5: Distribution of VGlut1- and VGlut2positive neurons in the mouse olfactory bulb. (A-D) Distribution pattern of VGluT2 and VGlut1 in the adult OB. VGluT1 in situ hybridization shows a strong signal in the $M C L$ and a weaker signal at the boundary of the EPL and GL (A). VGluT2 mRNA is found both in the $M C L$ and throughout the $G L(C)$. DAPI counterstaining $(B, D)$ allows the visualization of the distinct $\mathrm{OB}$ layers. (E-F) Graphs showing the quantification of the distribution of VGlut1 and VGlut2 in the different $O B$ cell layers. When we considered the VGluT-positive cells as a proportion of DAPI(+) cells, we found a similar distribution. VGluT1(+) cells accounted for around $14 \%$ of DAPI(+) cells in the MCL, EPL1, and EPL3, with a smaller proportion in EPL2 and GL1. VGluT2(+) cells were more widely distributed between the layers. In the GL as a whole, VGluT2 accounted for $15 \%$ of $\operatorname{DAPI}(+)$ cells, $19 \%$ in the MCL, and a lower proportion in the EPL.

Additional file 6: Figure S6: Local expression of GFP after dorsal electroporation of the lateral ventricle. (A-E) Native GFP expression observed 48 hours after electroporation of a GFP expression plasmid in the dorsal wall of the lateral ventricle of a newborn mouse at different caudo-rostral levels (from caudal (A) to rostral (E, showing the OB)). DAPI was used as a nuclear counterstain (blue). Scale bar: $1 \mathrm{~mm}$ in (A-D); $500 \mu \mathrm{m}$ in $(\mathrm{E})$

\section{Abbreviations}

4-OHT: 4-hydroxytamoxifen; BAC: bacterial artificial chromosome; bHLH: basic helix-loop-helix; CB: calbindin; CR: calretinin; E: embryonic day; EPL: external 
plexiform layer; GFP: green fluorescent protein; GL: glomerular layer; MCL: mitral cell layer; OB: olfactory bulb; P: postnatal day; PG: periglomerular; RMS rostral migratory stream; SVZ: subventricular zone; TH: tyrosine hydroxylase; VGluT: vesicular glutamate transporter; VZ: ventricular zone.

\section{Acknowledgements}

We are grateful to Dr Christophe Galichet for the generous gift of the iCreERT2 probe. This work was supported by grants from the DFG, including the excellence cluster CIPSM, by EUTRACC from the EU and the BMBF to MG and the Bavarian State Ministry of Sciences, Research, and the Arts (ForNeuroCell) to MG. EW is supported by a fellowship from the MRC, and MF and OR by grants from the Swiss National Fund (406340_128291 \& 31003A_127082). Research in the laboratory of FG is supported by funds from the Medical Research Council and grants from the European Commission Research and Technological Development program. MLP is a recipient of a collaborative career development fellowship in stem cell research offered by the Medical Research Council (MRC).

\section{Author details}

${ }^{1}$ Cambridge Centre for Brain Repair, Robinson Way, CB2 OPY Cambridge, UK. ${ }^{2}$ Division of Molecular Neurobiology, Medical Research Council - National Institute for Medical Research, NW7 1AA London, UK. ${ }^{3}$ Brain Research Institute, University of Zürich/ETHZ, 8057 Zürich, Switzerland. ${ }^{4}$ Department of Physiological Genomics, Institute of Physiology, Ludwig-Maximilians University Munich, 80636 Munich, Germany. ${ }^{5}$ Institute for Stem Cell Research, Helmholtz Zentrum München, 85764 Munich, Germany. ${ }^{6}$ Munich Center for Integrated Protein Science CiPSM, 81377 Munich, Germany.

\section{Authors' contributions}

EW, MLP, MEF, MSB and OR carried out the experimental work. FG and MLP generated the Neurog2iCreERT2 mouse. OR conceived of the study and wrote the manuscript. MG, FG, MEF and MSB participated in critical reading of the manuscript. All authors read and approved the final manuscript.

\section{Competing interests}

The authors declare that they have no competing interests.

Received: 22 October 2010 Accepted: 5 April 2011

Published: 5 April 2011

\section{References}

1. Hinds JW: Autoradiographic study of histogenesis in the mouse olfactory bulb. I. Time of origin of neurons and neuroglia. J Comp Neurol 1968, 134:287-304.

2. Bayer $\mathrm{SA}: 3 \mathrm{H}$-thymidine-radiographic studies of neurogenesis in the rat olfactory bulb. Exp Brain Res 1983, 50:329-340.

3. Vergano-Vera E, Yusta-Boyo MJ, de Castro F, Bernad A, de Pablo F, VicarioAbejon C: Generation of GABAergic and dopaminergic interneurons from endogenous embryonic olfactory bulb precursor cells. Development 2006, 133:4367-4379.

4. Wichterle H, Turnbull DH, Nery S, Fishell G, Alvarez-Buylla A: In utero fate mapping reveals distinct migratory pathways and fates of neurons born in the mammalian basal forebrain. Development 2001, 128:3759-3771.

5. Gritti A, Bonfanti L, Doetsch F, Caille I, Alvarez-Buylla A, Lim DA, Galli R, Verdugo JM, Herrera DG, Vescovi AL: Multipotent neural stem cells reside into the rostral extension and olfactory bulb of adult rodents. J Neurosci 2002, 22:437-445.

6. Doetsch F, Petreanu L, Caille I, Garcia-Verdugo JM, Alvarez-Buylla A: EGF converts transit-amplifying neurogenic precursors in the adult brain into multipotent stem cells. Neuron 2002, 36:1021-1034.

7. Altman J: Autoradiographic and histological studies of postnatal neurogenesis. IV. Cell proliferation and migration in the anterior forebrain, with special reference to persisting neurogenesis in the olfactory bulb. J Comp Neurol 1969, 137:433-457.

8. Bayer SA: Neuron production in the hippocampus and olfactory bulb of the adult rat brain: addition or replacement? Ann N Y Acad Sci 1985, 457:163-172.

9. Batista-Brito R, Close J, Machold R, Fishell G: The distinct temporal origins of olfactory bulb interneuron subtypes. J Neurosci 2008, 28:3966-3975.
10. Brill MS, Ninkovic J, Winpenny E, Hodge RD, Ozen I, Yang R, Lepier A, Gascon S, Erdelyi F, Szabo G, et al: Adult generation of glutamatergic olfactory bulb interneurons. Nature Neuroscience 2009, 12:1524-1533.

11. Englund C, Fink A, Lau C, Pham D, Daza RA, Bulfone A, Kowalczyk T, Hevner RF: Pax6, Tbr2, and Tbr1 are expressed sequentially by radial glia, intermediate progenitor cells, and postmitotic neurons in developing neocortex. J Neurosci 2005, 25:247-251.

12. Hevner RF, Hodge RD, Daza RA, Englund C: Transcription factors in glutamatergic neurogenesis: conserved programs in neocortex, cerebellum, and adult hippocampus. Neurosci Res 2006, 55:223-233.

13. Hodge RD, Kowalczyk TD, Wolf SA, Encinas JM, Rippey C, Enikolopov G, Kempermann G, Hevner RF: Intermediate progenitors in adult hippocampal neurogenesis: Tbr2 expression and coordinate regulation of neuronal output. J Neurosci 2008, 28:3707-3717.

14. Fode C, Ma Q, Casarosa S, Ang SL, Anderson DJ, Guillemot F: A role for neural determination genes in specifying the dorsoventral identity of telencephalic neurons. Genes Dev 2000, 14:67-80.

15. Britz $O$, Mattar $P$, Nguyen $L$, Langevin LM, Zimmer C, Alam S, Guillemot $F$, Schuurmans $C$ : A role for proneural genes in the maturation of cortical progenitor cells. Cereb Cortex 2006, 16(Suppl 1):i138-151.

16. Shepherd GM: Synaptic organization of the mammalian olfactory bulb. Physiol Rev 1972, 52:864-917.

17. Hayar A, Karnup S, Ennis M, Shipley MT: External tufted cells: a major excitatory element that coordinates glomerular activity. J Neurosci 2004, 24:6676-6685.

18. Aungst IL, Heyward PM, Puche AC, Karnup SV, Hayar A, Szabo G, Shipley MT: Centre-surround inhibition among olfactory bulb glomeruli. Nature 2003, 426:623-629.

19. Hayar A, Karnup S, Shipley MT, Ennis M: Olfactory bulb glomeruli: external tufted cells intrinsically burst at theta frequency and are entrained by patterned olfactory input. J Neurosci 2004, 24:1190-1199.

20. Schoenfeld TA, Macrides F: Topographic organization of connections between the main olfactory bulb and pars externa of the anterior olfactory nucleus in the hamster. J Comp Neurol 1984, 227:121-135.

21. Ozen I, Galichet C, Watts C, Parras C, Guillemot F, Raineteau O: Proliferating neuronal progenitors in the postnatal hippocampus transiently express the proneural gene Ngn2. Eur J Neurosci 2007, 25:2591-2603.

22. Hippenmeyer S, Vrieseling E, Sigrist M, Portmann T, Laengle C, Ladle DR, Arber S: A developmental switch in the response of DRG neurons to ETS transcription factor signaling. PLOS Biol 2005, 3:e159.

23. Kimura N, Nakashima K, Ueno M, Kiyama H, Taga T: A novel mammalian Tbox-containing gene, Tbr2, expressed in mouse developing brain. Brain Res Dev Brain Res 1999, 115:183-193.

24. Allen ZJ, Waclaw RR, Colbert MC, Campbell K: Molecular identity of olfactory bulb interneurons: transcriptional codes of periglomerular neuron subtypes. J Mol Histol 2007, 38:517-525.

25. Gabellec MM, Panzanelli P, Sassoe-Pognetto M, Lledo PM: Synapse-specific localization of vesicular glutamate transporters in the rat olfactory bulb. Eur J Neurosci 2007, 25:1373-1383.

26. Ohmomo H, Ina A, Yoshida S, Shutoh F, Ueda S, Hisano S: Postnatal changes in expression of vesicular glutamate transporters in the main olfactory bulb of the rat. Neuroscience 2009, 160:419-426.

27. Tamamaki N, Yanagawa Y, Tomioka R, Miyazaki J, Obata K, Kaneko T: Green fluorescent protein expression and colocalization with calretinin, parvalbumin, and somatostatin in the GAD67-GFP knock-in mouse. J Comp Neurol 2003, 467:60-79.

28. Chang YC, Gottlieb DI: Characterization of the proteins purified with monoclonal antibodies to glutamic acid decarboxylase. J Neurosci 1988, 8(6):2123-30.

29. Parrish-Aungst S, Shipley MT, Erdelyi F, Szabo G, Puche AC: Quantitative analysis of neuronal diversity in the mouse olfactory bulb. J Comp Neurol 2007, 501:825-836.

30. Kosaka K, Kosaka T: synaptic organization of the glomerulus in the main olfactory bulb: compartments of the glomerulus and heterogeneity of the periglomerular cells. Anat Sci Int 2005, 80:80-90.

31. Kosaka K, Kosaka T: Chemical properties of type 1 and type 2 periglomerular cells in the mouse olfactory bulb are different from those in the rat olfactory bulb. Brain Res 2007, 1167:42-55.

32. Panzanelli P, Fritschy JM, Yanagawa Y, Obata K, Sassoe-Pognetto M: GABAergic phenotype of periglomerular cells in the rodent olfactory bulb. J Comp Neurol 2007, 502:990-1002. 
33. Pinching AJ, Powell TP: The neuron types of the glomerular layer of the olfactory bulb. J Cell Sci 1971, 9:305-345.

34. Bertrand N, Castro DS, Guillemot F: Proneural genes and the specification of neural cell types. Nat Rev Neurosci 2002, 3:517-530.

35. Parras CM, Schuurmans C, Scardigli R, Kim J, Anderson DJ, Guillemot F: Divergent functions of the proneural genes Mash1 and Ngn2 in the specification of neuronal subtype identity. Genes Dev 2002, 16:324-338.

36. Hodge RD, Kowalczyk TD, Wolf SA, Encinas JM, Rippey C, Enikolopov G, Kempermann G, Hevner RF: Intermediate progenitors in adult hippocampal neurogenesis: Tbr2 expression and coordinate regulation of neuronal output. J Neurosci 2008, 28:3707-3717.

37. Molyneaux BJ, Arlotta P, Menezes JR, Macklis JD: Neuronal subtype specification in the cerebral cortex. Nat Rev Neurosci 2007, 8:427-437.

38. Whitman MC, Greer CA: Adult-generated neurons exhibit diverse developmental fates. Dev Neurobiol 2007, 67:1079-1093.

39. Kele J, Simplicio N, Ferri AL, Mira H, Guillemot F, Arenas E, Ang SL: Neurogenin 2 is required for the development of ventral midbrain dopaminergic neurons. Development 2006, 133:495-505.

40. Andersson E, Jensen JB, Parmar M, Guillemot F, Bjorklund A: Development of the mesencephalic dopaminergic neuron system is compromised in the absence of neurogenin 2. Development 2006, 133:507-516.

41. Dellovade TL, Pfaff DW, Schwanzel-Fukuda M: Olfactory bulb development is altered in small-eye (Sey) mice. J Comp Neurol 1998, 402:402-418.

42. Hack MA, Saghatelyan A, de Chevigny A, Pfeifer A, Ashery-Padan R, Lledo PM, Gèotz M: Neuronal fate determinants of adult olfactory bulb neurogenesis. Nat Neurosci 2005, 8:865-872.

43. Kohwi M, Osumi N, Rubenstein JL, Alvarez-Buylla A: Pax6 is required for making specific subpopulations of granule and periglomerular neurons in the olfactory bulb. J Neurosci 2005, 25:6997-7003.

44. Brill MS, Snapyan M, Wohlfrom H, Ninkovic J, Jawerka M, Mastick GS, Ashery-Padan R, Saghatelyan A, Berninger B, Gotz M: A dlx2- and pax6dependent transcriptional code for periglomerular neuron specification in the adult olfactory bulb. J Neurosci 2008, 28:6439-6452.

45. Toresson H, Potter SS, Campbell K: Genetic control of dorsal-ventral identity in the telencephalon: opposing roles for Pax6 and Gsh2. Development 2000, 127:4361-4371.

46. Yun K, Potter S, Rubenstein JL: Gsh2 and Pax6 play complementary roles in dorsoventral patterning of the mammalian telencephalon. Development 2001, 128:193-205.

47. Scardigli R, Baumer N, Gruss P, Guillemot F, Le Roux I: Direct and concentration-dependent regulation of the proneural gene Neurogenin2 by Pax6. Development 2003, 130:3269-3281.

48. Kohwi M, Petryniak MA, Long JE, Ekker M, Obata K, Yanagawa Y, Rubenstein $J$, Alvarez-Buylla A: A subpopulation of olfactory bulb GABAergic interneurons is derived from Emx1- and Dlx5/6-expressing progenitors. J Neurosci 2007, 27:6878-6891.

49. Boutin C, Diestel $\mathrm{S}$, Desoeuvre A, Tiveron MC, Cremer H: Efficient in vivo electroporation of the postnatal rodent forebrain. PLOS ONE 2008, 3 e1883.

50. Ezeh PI, Wellis DP, Scott JW: Organization of inhibition in the rat olfactory bulb external plexiform layer. J Neurophysiol 1993, 70:263-274.

51. Belluscio L, Lodovichi C, Feinstein P, Mombaerts P, Katz LC: Odorant receptors instruct functional circuitry in the mouse olfactory bulb. Nature 2002, 419:296-300.

52. Kosaka T, Kosaka K: Tyrosine hydroxylase-positive GABAergic juxtaglomerular neurons are the main source of the interglomerular connections in the mouse main olfactory bulb. Neurosci Res 2008, 60:349-354.

53. Kiyokage E, Pan YZ, Shao Z, Kobayashi K, Szabo G, Yanagawa Y, Obata K, Okano H, Toida K, Puche AC, Shipley MT: Molecular identity of periglomerular and short axon cells. J Neurosci 2010, 30:1185-1196.

54. Seibt J, Schuurmans C, Gradwhol G, Dehay C, Vanderhaeghen P, Guillemot F, Polleux F: Neurogenin2 specifies the connectivity of thalamic neurons by controlling axon responsiveness to intermediate target cues. Neuron 2003, 39:439-452.

55. Srinivas S, Watanabe T, Lin CS, William CM, Tanabe $Y$, Jessell TM, Costantini F: Cre reporter strains produced by targeted insertion of EYFP and ECFP into the ROSA26 locus. BMC Dev Biol 2001, 1:4.

56. De Paola V, Arber S, Caroni P: AMPA receptors regulate dynamic equilibrium of presynaptic terminals in mature hippocampal networks. Nat Neurosci 2003, 6:491-500.
57. Toth ZE, Mezey E: Simultaneous visualization of multiple antigens with tyramide signal amplification using antibodies from the same species. J Histochem Cytochem 2007, 55:545-554.

58. Lind D, Franken S, Kappler J, Jankowski J, Schilling K: Characterization of the neuronal marker NeuN as a multiply phosphorylated antigen with discrete subcellular localization. J Neurosci Res 2005, 79:295-302.

59. Chang YC, Gottlieb DI: Characterization of the proteins purified with monoclonal antibodies to glutamic acid decarboxylase. J Neurosci 1988, 8:2123-2130.

doi:10.1186/1749-8104-6-12

Cite this article as: Winpenny et al: Sequential generation of olfactory bulb glutamatergic neurons by Neurog2-expressing precursor cells. Neural Development 2011 6:12.

\section{Submit your next manuscript to BioMed Central and take full advantage of:}

- Convenient online submission

- Thorough peer review

- No space constraints or color figure charges

- Immediate publication on acceptance

- Inclusion in PubMed, CAS, Scopus and Google Scholar

- Research which is freely available for redistribution

Submit your manuscript at www.biomedcentral.com/submit
Ciomed Central 